\title{
Dearomatization Reactions of Indoles to Access 3D Indoline Structures
}

\author{
Hussein Abou-Hamdan a \\ Cyrille Kouklovskya \\ Guillaume Vincent*a \\ a Université Paris-Saclay, CNRS \\ Institut de Chimie Moléculaire et des Matériaux d'Orsay \\ (ICMMO) \\ 91405, Orsay, France91405, Orsay France \\ Guillaume.vincent@universite-paris-saclay.fr \\ Click here to insert a dedication.
}<smiles>[R]c1c([R])n([R])c2ccccc12</smiles><smiles>CCCCC</smiles>

\section{Received:
Accepted:
Published onlin \\ DOI:}

Abstract This account summarizes our involvement in the development of dearomatization reactions of indoles that has for origin a total synthesis problematic. We present the effort from our group to obtain 3D-indolines scaffold from the umpolung of $\mathrm{N}$-acyl indoles via activation with $\mathrm{FeCl}_{3}$, to the oxidative spirocyclizations of N-EWG indoles and via the use of electrochemistry.

Key words Indole, dearomatization, indolines, $\mathrm{FeCl}_{3}$, radical chemistry, electrochemistry

\section{Introduction}

Indoline derivatives are three dimensional structures of interest in the context of drug discovery. ${ }^{1}$ In this context, the overall purpose of our research program is the development of new synthetic methods for the dearomatization of the indole nucleus to access such structures (Scheme 1). ${ }^{2}$ A dearomative process allows to transform a plain and achiral compound into a chiral scaffold. $^{3}$

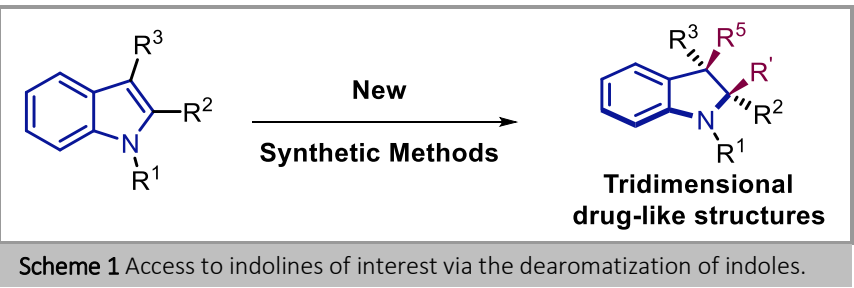

The starting point of our endeavors in this research field was our desire to perform the total synthesis of ent-azonazine (4), a benzofuroindoline-containing 5 natural product which biosynthesis implies the oxidative coupling of the indole and phenol parts of diketopiperazine $\mathbf{3}$ (Scheme 2). Inspired by the impressive Harran's total synthesis of diazonamide A (2) via benzofuroindoline $\mathbf{2}$ from tripeptide derivative $1,{ }^{6}$ we planned to perform a bioinspired dearomative oxidative cyclization mediated by a hypervalent reagent such as PIFA or PIDA. ${ }^{7}$ This procedure involved the oxidation of the phenol into a highly electrophilic phenoxenium species which is immediately attacked by the nucleophilic indole. Unfortunately, all our attempts met with failures leading to mixtures of intractable oxidized products. Yao was more persistent than us. Few years after our attempts, his research group was able to achieve the oxidative cyclization of tryptophan-tyrosine diketopiperazine $\mathbf{3}$ leading to over-oxidized benzofuroindoline $\mathbf{5}$ which was eventually converted into ent-azonazine (4). ${ }^{8}$

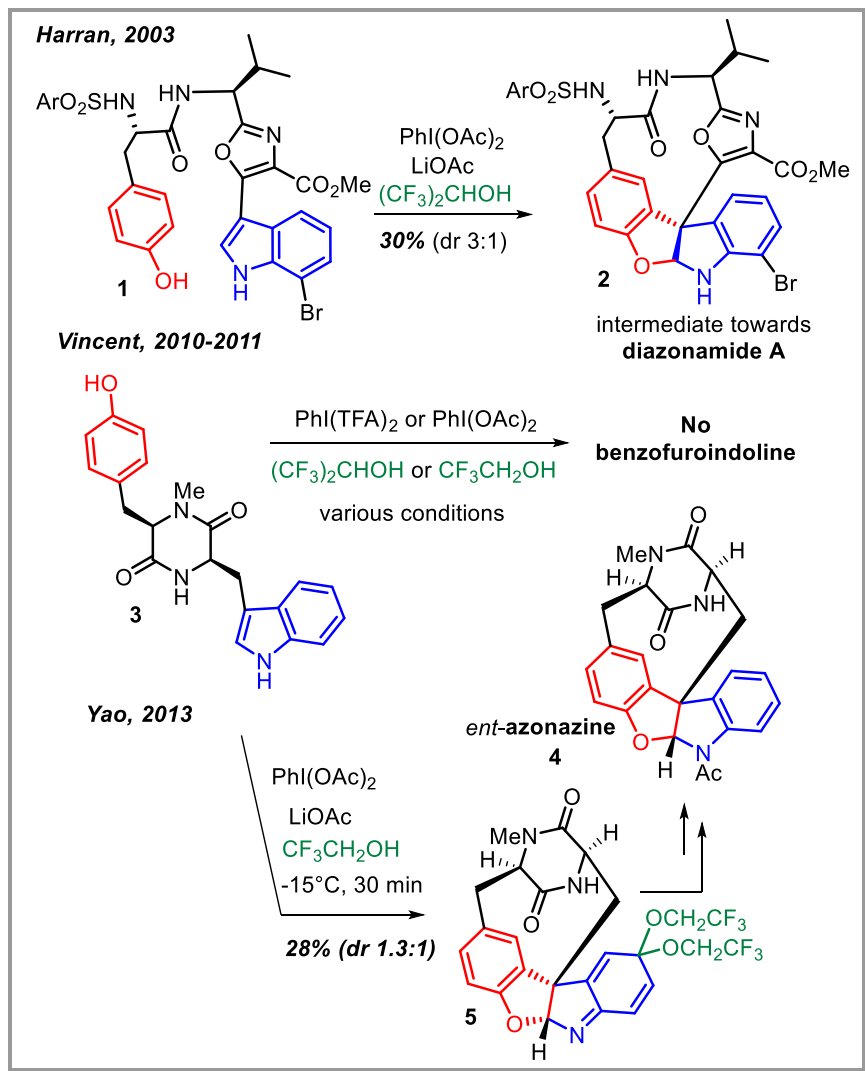

Scheme 2 Hypervalent-mediated oxidative coupling of indoles and phenols 
The Harran's oxidative coupling between indoles and phenols mediated by PIDA is unfortunately quite substrate dependent. Not only the oxidative cyclization of diketopiperazine $\mathbf{3}$ toward azonazine (4) is capricious, but an intermolecular version also invariably failed in our hands.

While our incapacity to form the benzofuroindoline framework of azonazine was frustrating at that time, it was retrospectively an opportunity. It encouraged us to initiate a new research program which led us to investigate alternative dearomatization reactions of indoles.

After having considered various tactics without success, we turned our attention towards the reversion of polarity of indoles (Scheme 3). Rather than using the innate C3-nucleophilicity of indoles, our dearomatization strategies mainly relies on an umpolung process leading to the generation of electrophilic indolenium derivatives which can be further functionalized. ${ }^{9}$

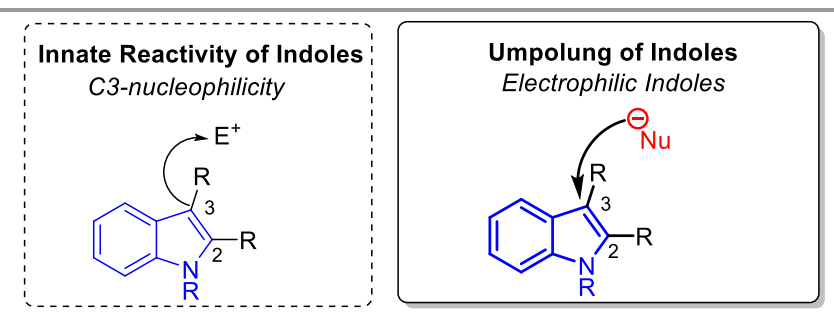

Scheme 3 Generation of electrophilic indoles.

\section{Activation of $\mathrm{N}$-acyl indoles with $\mathrm{FeCl}_{3}$}

\subsection{Hydroarylation of $\mathrm{N}$-acyl indoles}

In our effort toward the synthesis of azonazine, we aimed to discover a general method to achieve a regioselective dearomative introduction of aryl groups at the C3-position of indoles $^{1 \mathrm{~b}}$ and eventually to access benzofuroindolines. As we already discussed it in a previous Synpact article,5a we were inspired by a report from Nakatsuka and co-workers, which described the regioselective C3-hydroarylation of N-Ac indoles 6 into 3-arylindolines 8 mediated by a large excess of $\mathrm{AlCl}_{3}$ with the creation of one stereogenic center in a racemic form (Scheme 4). ${ }^{10}$ Very interestingly in this reaction, the C3-position of N-Ac indole 6 could be formally considered as electrophilic. ${ }^{9}$ This work was published in a journal ${ }^{10 a}$ which is not widely access by the community of synthetic organic chemists and was unfortunately unnoticed despite its very high synthetic potential. Nevertheless, this method seemed well suited to access benzofuroindolines $\mathbf{1 1}$ Unfortunately, the reaction could not proceed with phenols $\mathbf{9}$ as nucleophiles in presence of $\mathrm{AlCl}_{3}$ as the promotor. Investigation of various Lewis acids resulted in the discovery of $\mathrm{FeCl}_{3}$ as a very potent mediator of the hydroarylation of N-Ac indoles 6 by phenols 9.11 The 3-(2-hydroxyphenyl)-N-Ac-indolines 10 obtained were then converted into benzofuroindolines 11. Since the direct oxidation of $\mathbf{1 0}$ did not lead to the corresponding N-Ac benzofuroindolines, we removed the acetyl group in acidic conditions. Subsequently, oxidation of the indoline with TPAP and NMO or diisopropylazodicarboxylate (DIAD) led directly to the expected benzofuroindolines $\mathbf{1 1}$ in which indeed the fused benzofurane and indoline parts are cis.

The development of a catalytic enantioselective version of this hydroarylation reaction is highly desirable. However, it is a difficult task that we are currently investigating. In the meantime, we relied on the use of a $\mathrm{N}$-acyl chiral auxiliary derived from proline on 12 that delivered a modest diasteroselectivity. Nevertheless, after separation, the major diastereoisomer 13a could be converted into a benzofuroindoline 11a with a $94 \%$ ee.

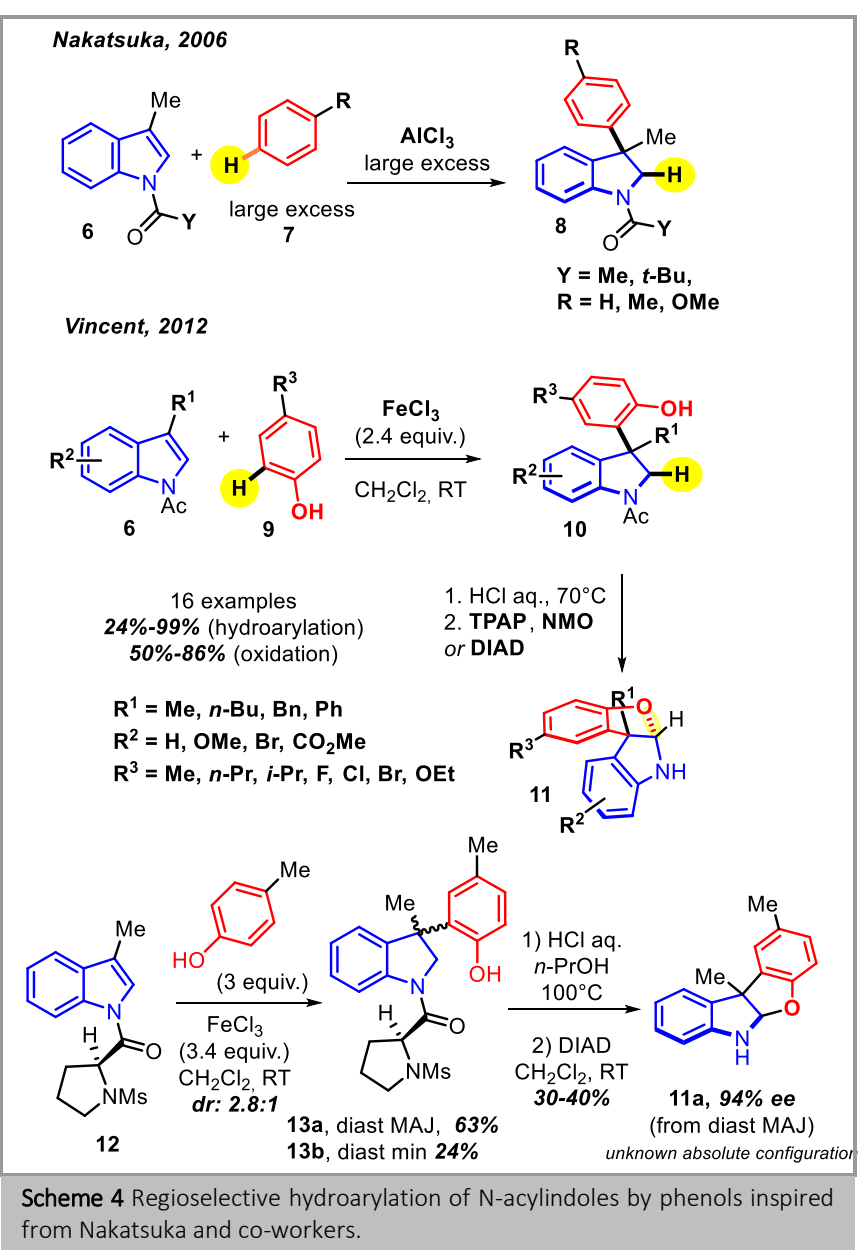

Since a limited number of substrates were investigated by Nakatsuka and since we found that $\mathrm{FeCl}_{3}$ is a better promoter than $\mathrm{AlCl}_{3}$, we decided to perform a thorough investigation of the hydroarylation of N-Ac indoles 6 (Scheme 5). ${ }^{12}$ Various electronrich arenes $\mathbf{7}$ such as anisole, thioanisole, trimethoxybenene, toluene, xylenes or naphtalenes could be employed as the nucleophilic entity leading to 3 -arylindolines $\mathbf{8}$. Very interestingly, we were also able to add some heterocyclic aromatic nucleophiles including N-Ts indole, 3methylbenzofuran and thiophene derivatives. Concerning the substitution of the indole moiety, both electron-donating groups, halogens and electron withdrawing groups on the benzene part are tolerated. It is noticeable that the reaction is faster with electron-donating groups: while the reaction is finished is less than $1 \mathrm{hr}$ with a methoxy group at the C5-position, $48 \mathrm{hrs}$ are necessary for a nitro group at the same position. The C3-position tolerates phenyl, benzyl as well as alkyl substituents with functional groups such as ester or bromide. However, the presence of a nitrogen-containing group on the C3-alkyl chain completely inhibits the reaction. 


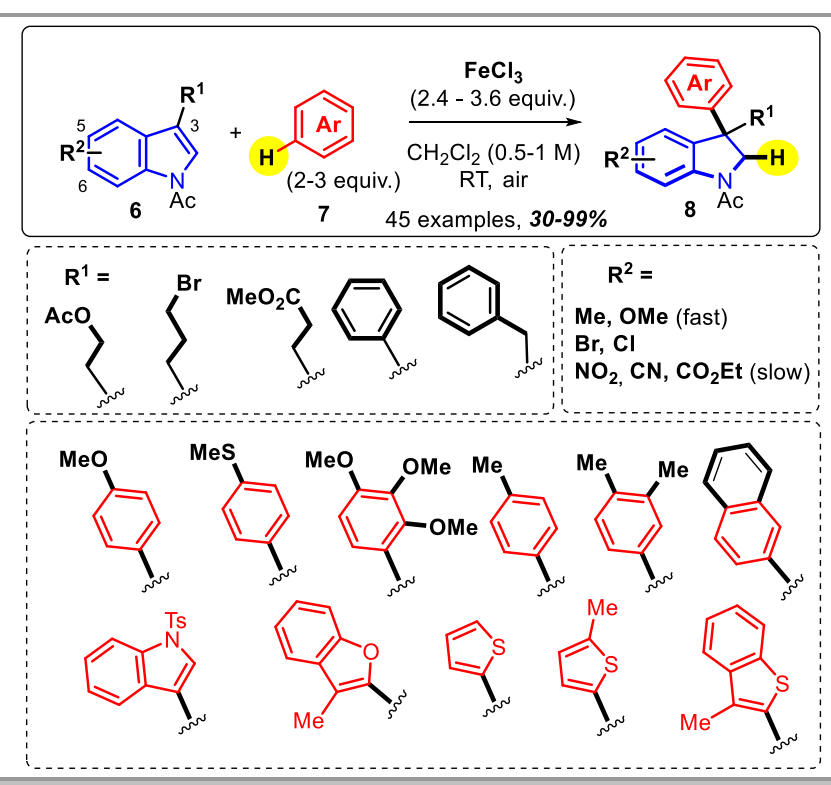

Scheme 5 General regioselective C3-hydroarylation of $\mathrm{N}$-Ac indoles mediates by $\mathrm{FeCl}_{3}$.

We recently extended this method to an intramolecular version (Scheme 6). 3,3-Spiroindolines 15, which are molecules of biological interest, ${ }^{13}$ were obtained when the arene nucleophile is attached at the C3-position of indole $\mathbf{1 4}$ by a three carbonstethered..$^{14}$ In contrast, a shorter tether in $\mathbf{1 6}$ led a to a C2hydroarylation and to cis-tetracyclic compounds $\mathbf{1 7 . 1 5}$

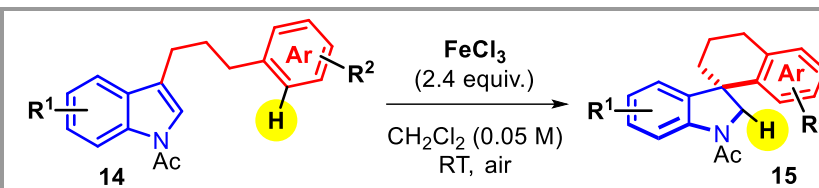

23 examples, $21-79 \%$

$\mathrm{R}^{1}=\mathrm{H}, \mathrm{OMe}, \mathrm{Me}, \mathrm{Cl}, \mathrm{Br} ; \mathrm{R}^{2}=\mathrm{H}, \mathrm{OMe}, \mathrm{Me}$ or $\mathrm{Ar}=$ thienyl

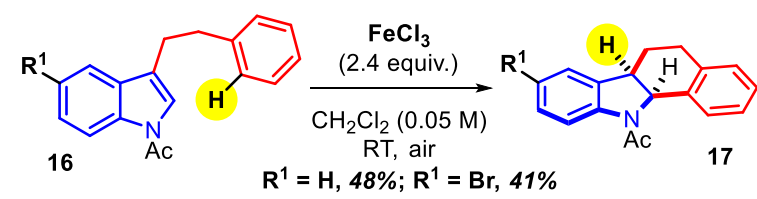

Scheme 6 Intramolecular hydroarylation.

Having intensively studied the scope of 3-substituted N-Ac indoles in the 3-hydroarylation reaction, we wondered what would be the outcome with $\mathrm{N}$-Ac indoles 18 lacking a substituent at the $\mathrm{C} 3$ position of $\mathrm{N}-\mathrm{Ac}$ indoles.

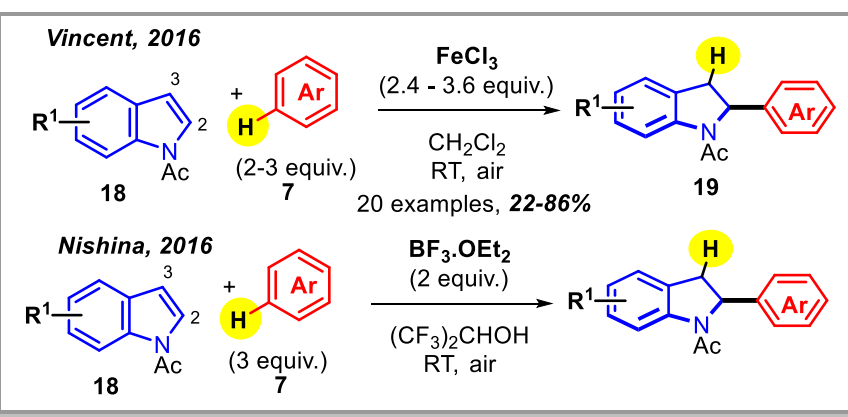

Scheme 7 Regioselective C2-hydroarylation of 3-unsubstituted-N-Ac-indoles.

We learned that the regioselectivity was dependent of the substitution of the C3 position since exclusively 2-aryl-N-Ac indolines 19 were obtained (Scheme 7). ${ }^{15}$ Simultaneously to this work, Nishina reported the same transformation with boron trifluoride etherate in hexafluoro-iso-propanol (HFIP) but probably with a distinct mechanism since in the case of a 3substituted indole, the 2-aryl-indoline is also obtained in a modest yield instead of the 3 -arylindoline of type $\mathbf{8}{ }^{16}$

We then gathered mechanistic insights of this general hydroarylation reaction which requires 2 equivalents of $\mathrm{FeCl}_{3} .{ }^{17}$ In situ IR analysis and the isolation of a $\mathrm{FeCl}_{3}$-(skatole $\left.\mathrm{N}-\mathrm{Ac}\right)_{2}$ complex suggests a pre-activation of the carbonyl of $\mathrm{N}$-Ac skatole by $\mathrm{FeCl}_{3}$ such as in Ia via respective collaborations with Alejandro Perez-Luna from Pierre and Marie Curie University of Paris- 6 and Nourredine Ghermani of the Faculty of pharmacy of Université Paris-Sud (Scheme 8). This activation would probably increase the delocalizing of the nitrogen lone pair into the carbonyl system. Thus the nitrogen lone-pair would be less delocalized into the enamide system and therefore the electron density at the C3 position would decrease. High resolution X-ray diffraction of the $\mathrm{FeCl}_{3}$-(skatole $\left.\mathrm{N}-\mathrm{Ac}\right)_{2}$ complex and of $\mathrm{N}$-Ac skatole allowed us to experimentally observed that the coordination of $\mathrm{FeCl}_{3}$ to the acetyl group could induce the reversal of polarity of the C3position. In addition, a Hammett's study which takes into account the electronic parameters of the substituents in position 5 and 6 suggests the existence of positive charges on the indolic nitrogen and the $\mathrm{C} 3$ position of the indole.

The kinetic isotopic effect (KIE = 1 for toluene vs toluene-d8 as nucleophile), indicates that the rupture of the $\mathrm{CH}$ bond of the nucleophile is not the rate determining step of the reaction which seems in agreement with a Wheland type intermediate and a Friedel- Crafts type mechanism (very fast $\mathrm{CH}$ cleavage).

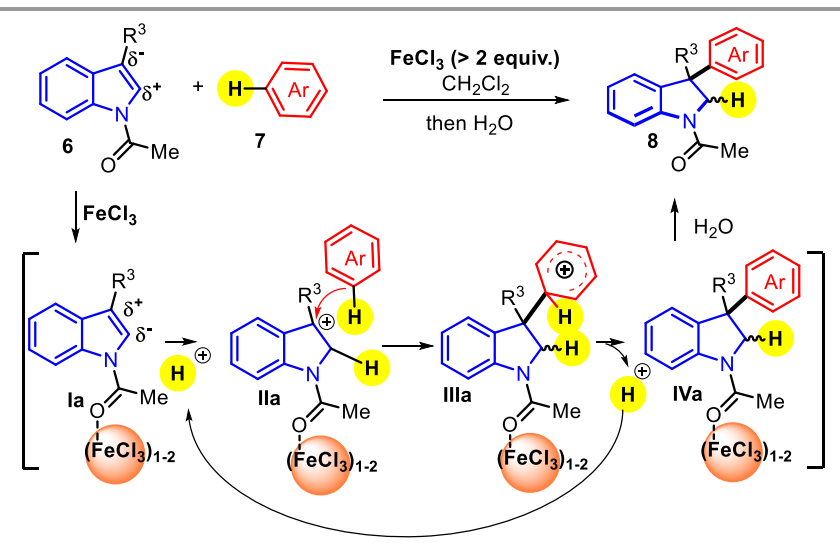

in-situ IR, DFT, Hammett, KIE, high resolution X-ray analysis
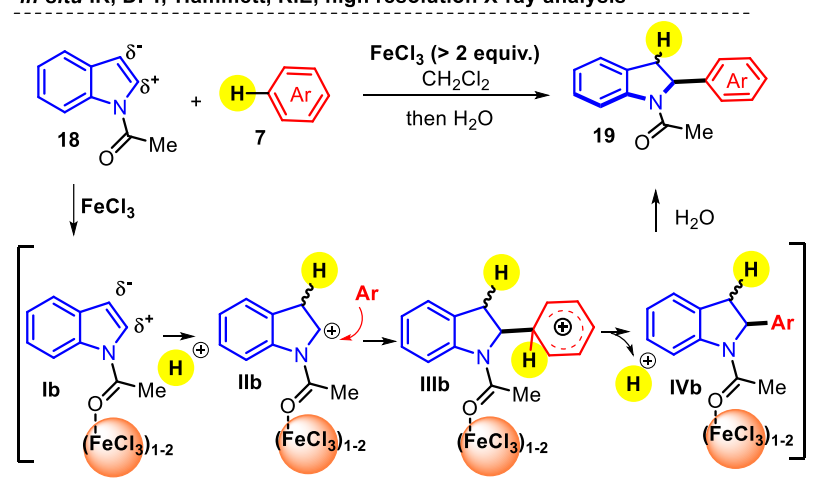

Scheme 8 Mechanistic hypothesis. 
After formation of a complex such as $\mathbf{I}$ between $\mathrm{FeCl}_{3}$ and $\mathrm{N}-\mathrm{Ac}$ indole 6 resulting in the umpolung of the C3-position of the indole nucleus, we thought that a second $\mathrm{FeCl}_{3}$ molecule would activate the $\mathrm{C} 2=\mathrm{C} 3$ double bond, however this mechanistic pathway was invalidated by DFT calculations performed by Vincent Gandon from our institute. It was rather suggested that it is a proton which activates the $\mathrm{C} 2=\mathrm{C} 3$ double bond (II) to induce the attack of the aromatic nucleophile and the creation of a Wheland intermediate III. The reaction is probably initiated by traces of $\mathrm{HCl}$ from the hydrolysis of $\mathrm{FeCl}_{3}$ in air. Then aromatisation of the Wheland intermediate would stoichiometrically deliver a proton and IV.

NBO charge calculations by DFT have shown that in the case of a 3-substituted indole, the $\mathrm{C} 2$ position becomes the most nucleophilic upon formation of complex Ia between the acetyl and $\mathrm{FeCl}_{3}$. Thus the proton will be introduced in position $\mathrm{C} 2$, generating a positive charge in C3 (IIa) which can be attacked by the electron-rich arene. On the other hand, in the case of an indole which is not substituted at $\mathrm{C} 3$, in spite of the association between $\mathrm{FeCl}_{3}$ and acetyl, the $\mathrm{C} 3$ position of $\mathbf{I b}$ remains the most nucleophilic, which would explain the inversion of regioselectivity.

An initial screening of Brønsted acids such as $\mathrm{HCl}$ proved to be unsuccessful to perform this hydroarylation process. Unfortunately, at that time, we did not envision strong enough Brønsted acids. Inspired by the mechanistic hypothesis with $\mathrm{FeCl}_{3}$, we recently discovered that all of our hydroarylation reactions of N-Ac indoles 6 could be performed with triflic acid or sulfuric acid instead of $\mathrm{FeCl}_{3}$ (Scheme 9). ${ }^{18}$ In situ IR, NMR or Hammett studies suggest a mechanism similar to the one with $\mathrm{FeCl}_{3}$ : one proton will activate the acetyl of indole and another proton will activate the $\mathrm{C} 2=\mathrm{C} 3$ bond $(\mathbf{V})$. DFT calculations have determined that the transition state for the protonation of the indole leading to carbocation $\mathbf{V}$ in presence of $\mathrm{TOH}$ has an energy barrier similar to the one leading to IIa in presence of $\mathrm{FeCl}_{3}$.

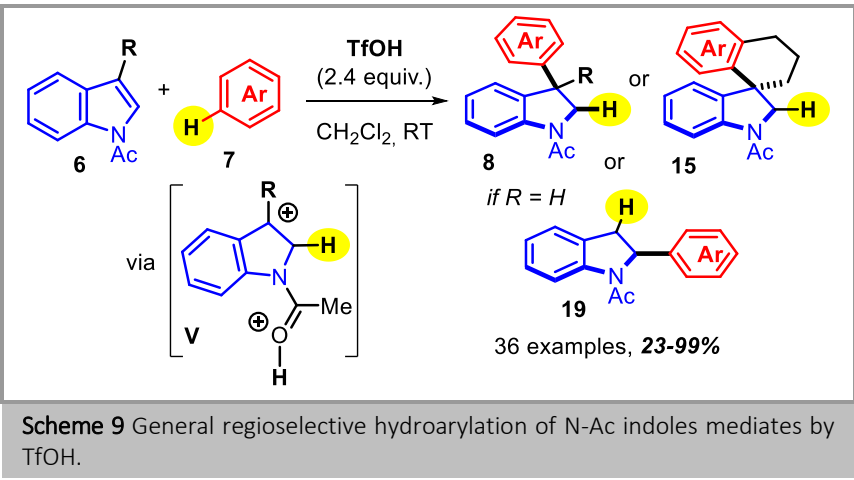

\subsection{Difunctionalization of $N$-acyl indoles}

In order to achieve a direct oxidative coupling between indoles and phenols, we decided to take advantage of the singular reactivity of $\mathrm{N}$-Ac indoles 6 activated by $\mathrm{FeCl}_{3}$.

In fact, just after we published the regioselective hydroarylation of N-Ac indoles by phenols, the group of Lei reported the oxidative coupling of electron-rich phenols $\mathbf{2 0}$ with styrenes $\mathbf{2 1}$ (Scheme 10).19 In the presence of DDQ and $\mathrm{FeCl}_{3}$, phenol is oxidized into carbon-centered radical intermediate VI. These conditions appeared to us to be perfectly compatible with the activation of $\mathrm{N}-\mathrm{Ac}$ indoles by $\mathrm{FeCl}_{3}$. The phenoxyl radical VI is added regioselectively in position $\mathrm{C} 2$ of 3-substituted-N-Ac indoles Ia activated by $\mathrm{FeCl}_{3}$ in order to form benzofuro[3,2$b$ ]indolines 23 (Scheme 10). ${ }^{20}$ The latter cis-fused framework is related to the natural product phalarine and is regioisomeric to the benzofuro[2,3- $a$ ] indolines obtained in our two stages process of scheme 4. Interestingly, with $\mathrm{N}-\mathrm{Ac}$ indoles equally substituted at the C2 and C3 positions, regioisomeric benzofuro[2,3a] indolines $\mathbf{2 4 a}$ and $\mathbf{2 4 b}$ were obtained.

It should be noted that this work was recently reinvestigated by the Lei group in electrochemical conditions with improvements of yields and scope of $\mathbf{2 3}$ (Scheme 11). ${ }^{21}$ The reaction proceeds via direct oxidation of the indole nucleus at the anode without the need of $\mathrm{FeCl}_{3}$ and DDQ.

Eventually, the Jia group performed a similar transformation with PIDA as oxidant to achieve the total synthesis of phalarine (Scheme 11).22 In this case, it is likely that phenol 25 is oxidized into an electrophilic reagent. The benzoyl group on the indole nitrogen of tetrahydo- $\beta$-carbazole $\mathbf{2 6}$ is crucial to obtain the optimal yield of the desired regioisomer 27.

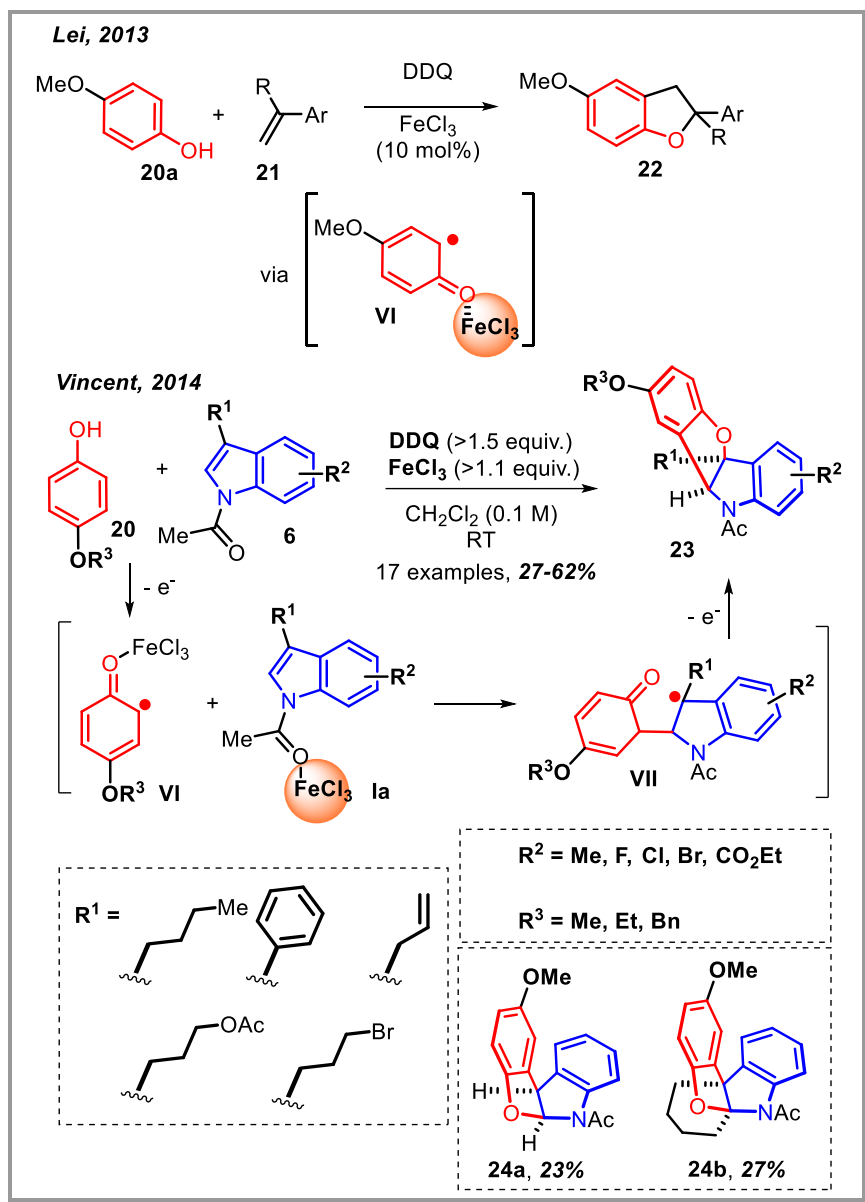

Scheme $10 \mathrm{FeCl}_{3}$-mediated direct oxidative coupling of indoles and $\mathrm{N}$-acyl indoles for the synthesis of benzofuroindolines. 


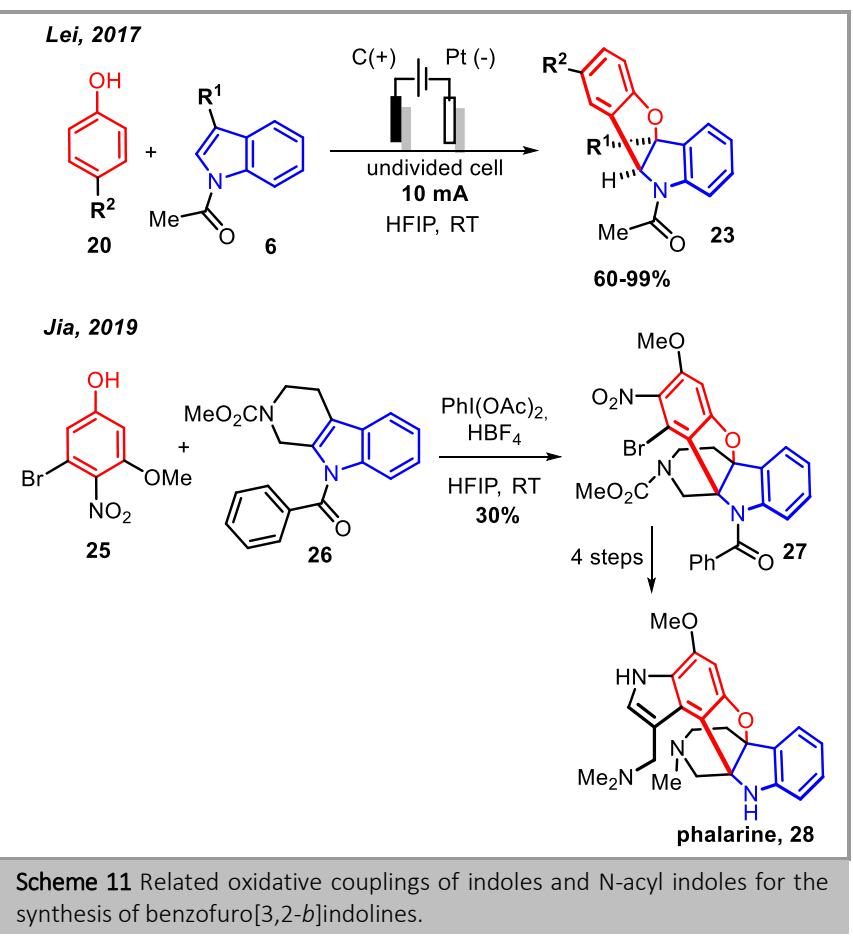

In order to increase the diversity of the 3-functionalized indolines that we could obtain by the $\mathrm{FeCl}_{3}$ activation of $\mathrm{N}$-Ac indoles, instead of electron-rich arenes, we investigated other $\pi$ nucleophiles such as allylsilanes. We have thus, performed in 2018 an unexpected 2,3-diallylation of $\mathrm{N}$-Ac indoles with $\mathrm{FeCl}_{3}$ (Scheme 12).23

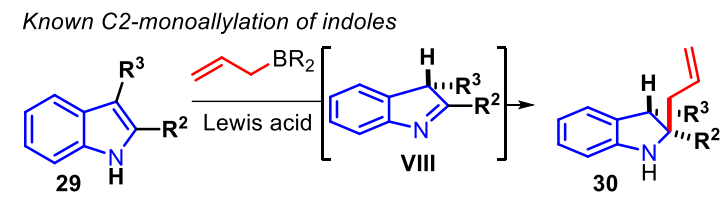

Unexpected $\mathrm{C}_{2} \mathrm{C} 3$-diallylation of $\mathrm{N}-\mathrm{Ac}$ indoles with $\mathrm{FeCl}_{3}$<smiles>[R]C(=O)n1c([R])c([R])c2cc[R14]cc21</smiles>

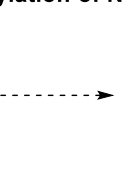

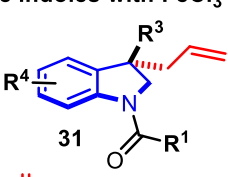
expected but

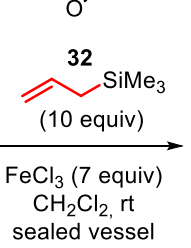

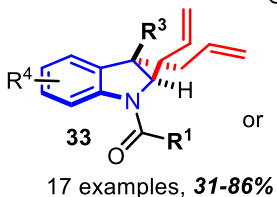
17 examples, $31-86 \%$ $\mathrm{dr}>85: 15$ $\mathbf{R}^{1}=\mathrm{Me}, \mathrm{H}, \mathrm{OEt}$ $\mathbf{R}^{3}=$ alkyl or aryl $\mathbf{R}^{4}=\mathrm{Me}, \mathrm{F}$, OMe

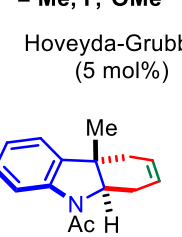

$35,77 \%$

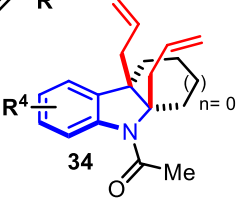

4 examples $18-39 \%$ $d r>95: 5$

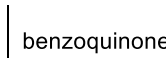
$(10 \mathrm{~mol} \%)$ $\mathrm{CH}_{2} \mathrm{Cl}_{2}, 40^{\circ} \mathrm{C}$

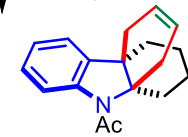

$36,69 \%$

Scheme $12 \mathrm{FeCl}_{3}$-mediated diallylation of $\mathrm{N}$-acyl indoles.

In fact, we expected to obtain C3-monoallylated indolines $\mathbf{3 1}$. This method would have been complementary to the C2allylation of indoles with allylboranes in presence of a Lewis acid via isomerisation of the enamine part of indole into imine VIII delivering 30.24 Surprisingly, the monoallylated compound $\mathbf{3 1}$ was never observed from allyltrimetylsilane $\mathbf{3 2}$ and $\mathrm{N}-\mathrm{Ac}$ indole 6 in presence of $\mathrm{FeCl}_{3}$. Instead, we noted the formation of the 2,3diallylated indolines $\mathbf{3 3}$ (Scheme 12). In order to ensure decent yields, we used a large excess of the allylsilane $\mathbf{3 2}$ and of the iron promotor in a sealed vessel and we studied the scope of this diallylation reaction.

On the indole nitrogen, other electron-withdrawing groups than the acetyl, were tolerated such as formyl and ethyloxy carbonyl functions. Diallylated indolines $\mathbf{3 3}$ were still obtained with hindered alkyl or aryl substituents at the C3-position. Electrondonating groups and fluoride on the benzene part of the indole afforded the expected diallylated indolines 33. Unfortunately, in the presence of electron-withdrawing groups the diallylation did not proceed. As demonstrated by X-ray analysis, trans-diallylated indolines $\mathbf{3 3}$ were isolated as the major isomers starting from 3substituted indoles. In contrast, cis-diallylated indolines 34 were synthesized from 2,3-disubstituted indoles.

The synthetic potential of the diallylated indolines obtained by this reaction was then demonstrated by applying different transformations to the olefins including a Heck reaction or a reduction of the two double bonds or the selective hydration of one of the alkene (not shown). In particular, the ring-closing metathesis was investigated and delivered cyclic compounds in good yields from the cis or trans indolines leading to tricyclic or tetracyclic indolines $\mathbf{3 5}$ and $\mathbf{3 6}$ (Scheme 12).

From a mechanistic point of view, several hypotheses are possible to explain this dearomative diallylation (Scheme 13).

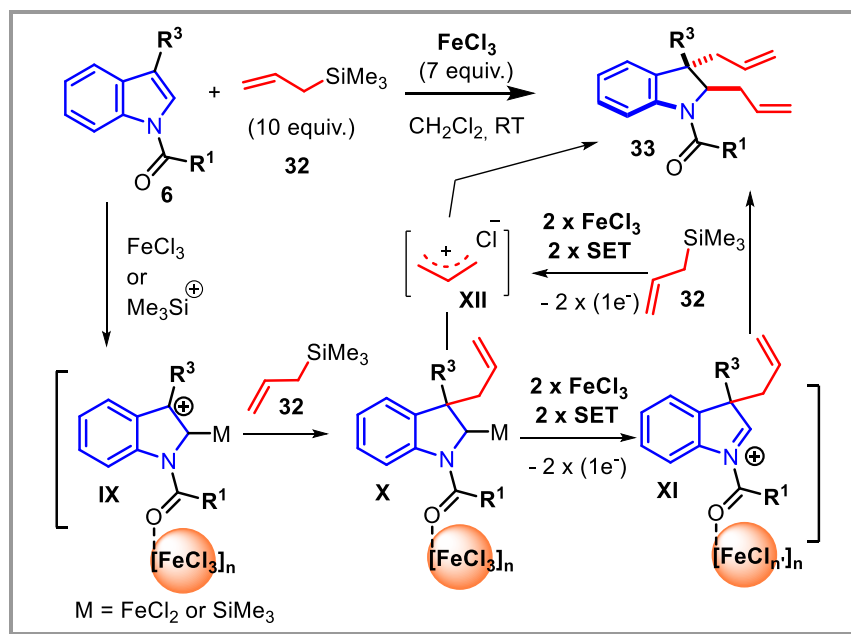

Scheme 13 Mechanistic proposal for the $\mathrm{FeCl}_{3}$-mediated diallylation of $\mathrm{N}$-acyl indoles

In contrast with our previous hydroarylation, no protons are released stoichiometrically during the reaction in order to activate the $\mathrm{C} 2=\mathrm{C} 3$ bond. Here, we could hypothesize that the activation of the double bond was promoted either by $\mathrm{FeCl}_{3}$ or by a trimethyl silyl cation generated by the reaction between allyltrimethylsilane $\mathbf{3 2}$ and $\mathrm{FeCl}_{3}$. This activation would lead to the formation of carbocation IX at C3, which can be trapped by allylsilane $\mathbf{3 2}$ to form intermediate $\mathbf{X}$. From this point, we can postulate several scenarios. Two single electron transfer (SET) oxidations of $\mathbf{X}$ with $\mathrm{FeCl}_{3}$ would delivered iminium $\mathbf{X I}$ which could react with a second molecule of allylsilane $\mathbf{3 2}$ to lead to 2,3- 
diallylated indoline 33. Alternatively, oxidation of allylsilane $\mathbf{3 2}$ with $\mathrm{FeCl}_{3}$ would lead to allylic cation XII which would be attacked by the carbon-metal bond of $\mathbf{X}$.

While studying reaction between alkenes and $\mathrm{N}$-Ac indoles activated by $\mathrm{FeCl}_{3}$, we were surprised to observe in two occasions a formal [2+2] cycloaddition with the $\mathrm{C} 2=\mathrm{C} 3$ double bond of the indole nucleus. During the synthesis of spirocyclic indolines in 2016 (cf Scheme 6), we replaced in one occasion the arene by a terminal olefin. ${ }^{14}$ We thought that a ene-type reaction would occur via XIII and would lead to spirocyclic-cyclohexenylindoline 38. It was again surprising to us to obtain cyclobutanic indoline 39, yet a spirocycle, but with a fused 5,4,5-tricyclic skeleton which structure was unambiguously verified by X-ray analysis (Scheme 14). It should be noted that You and Zheng described latter on a related reaction under light irradiation. ${ }^{25}$ We observed the second case of a [2+2] annulation during the reaction of $\mathrm{N}-\mathrm{Ac}$ cyclopentaindole $\mathbf{4 0}$ and allylsilane in 2018. ${ }^{23}$ Along with the diallylated compound 34a which was the minor compound, we obtained $34 \%$ of cyclobutane $\mathbf{4 1}$. We postulated that after activation of the $\mathrm{C} 2=\mathrm{C} 3$ bond and attack of the trimethylallylsilane, the $\beta$-silyl carbocation XIII could be intramolecularly intercepted by the nucleophilic carbon at C3 before elimination of the trimethylsilyl cation, eventually leading to 41 .

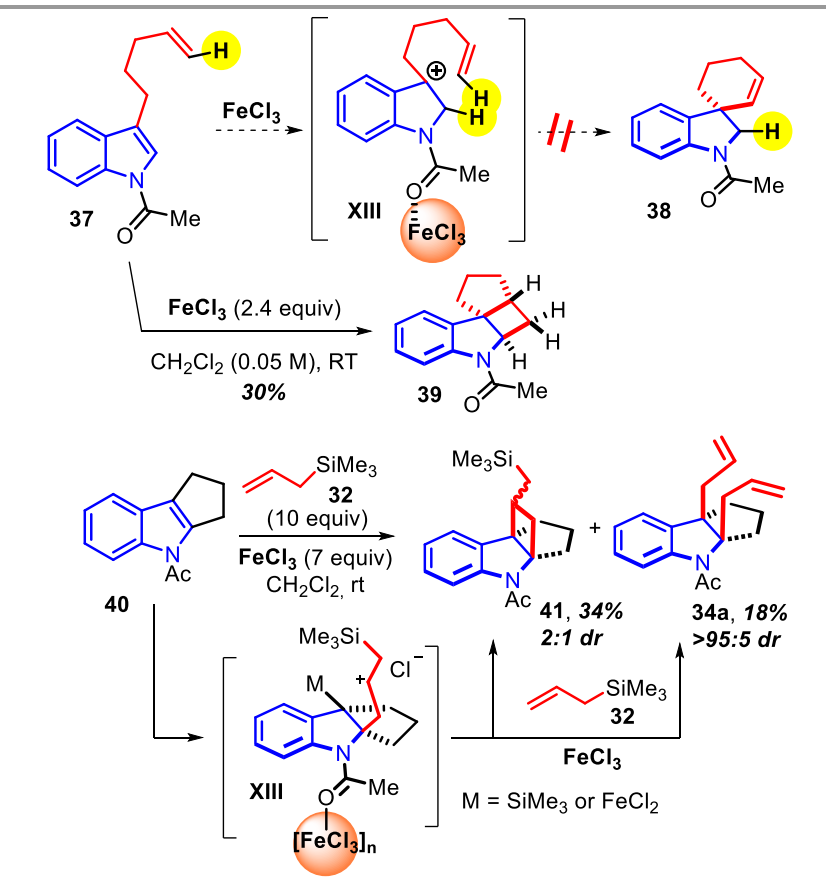

Scheme 14 Two cases of $\mathrm{FeCl}_{3}$-mediated [2+2] formal cycloaddition between alkenes and $\mathrm{N}$-Ac indoles.

The unexpected observation of this first [2+2] annulation encouraged us to dive further into cycloaddition reactions of $\mathrm{N}$ Ac indoles activated with $\mathrm{FeCl}_{3}$. A great number of reports dealing with cycloadditions/annulations applied to the innate C3nucleophilic character of indoles has been described in the literature. ${ }^{26}$ In these studies, the C3-position of the indole adds to the electrophilic atom of a dipole or a diene, and the $\mathrm{C} 2$ indole position is intercepted by the nucleophilic part of the dipole or diene. With our "umpolung of indoles" in mind, we aimed to invert this innate regioselectivity of cycloadditions. At this point, we started a collaboration with Xavier Moreau and Vincent Coeffard at the Université of Versailles and Isabelle Chataigner at the Université of Rouen, both in France. One of our idea was to exploit the expertise of Xavier Moreau and Vincent Coeffard in organocatalyzed [4+2] cycloadditions of dienals $\mathbf{4 2}^{27}$ and to merge it with $\mathrm{N}$-Ac indoles activated by $\mathrm{FeCl}_{3}$ Ia in order to obtain Diels-Alder cycloadducts $\mathbf{4 3}$ in an enantiopure form via trienamine intermediate XIV (Scheme 15). Once again, an unexpected event occurred when the experiments were performed in Versailles in the team of Xavier Moreau. ${ }^{28}$

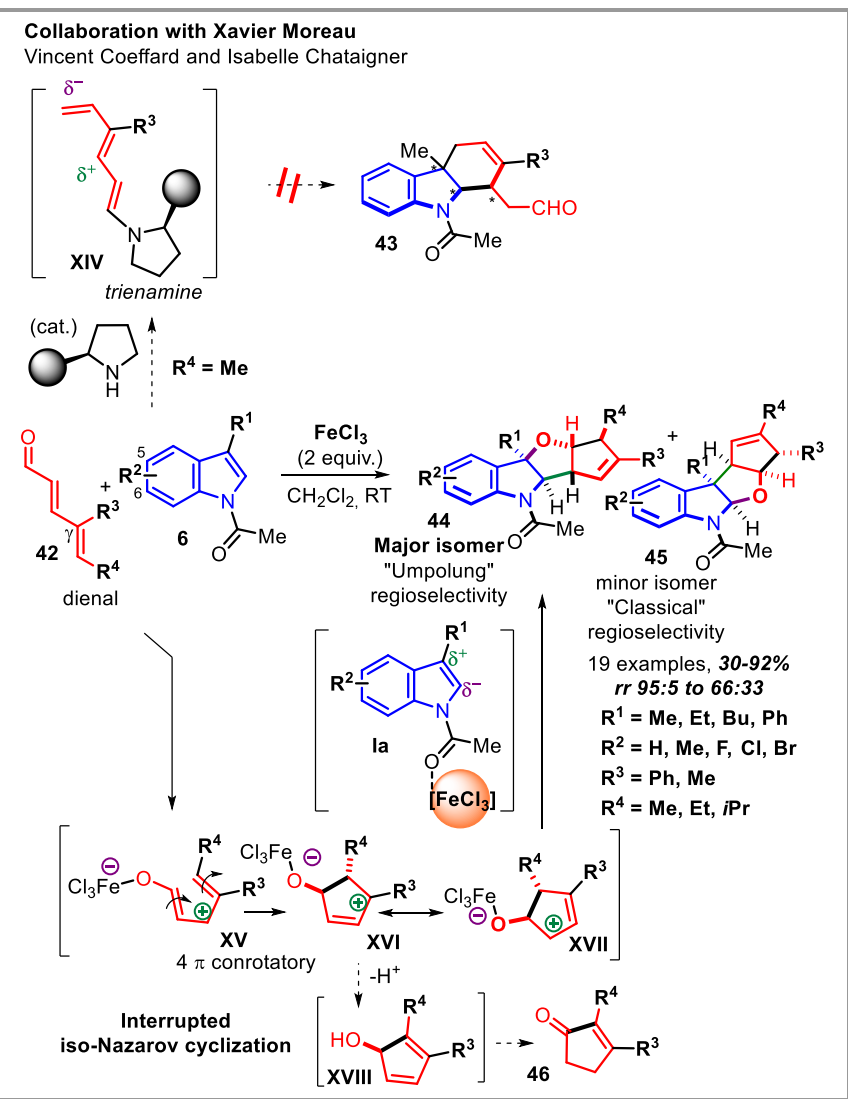

Scheme $15 \mathrm{FeCl}_{3}$-mediated domino interrupted iso-Nazarov/dearomative $(3+$ 2)-cycloaddition of N-Ac indoles.

The [4+2] cycloadduct $\mathbf{4 3}$ was never observed. Instead unexpected dearomatized products were formed. It turned out that the proline-derived catalyst was useless and 2 equivalents of $\mathrm{FeCl}_{3}$ were necessary to promote the reaction. It took us some times to resolve the structures of the compounds obtained which we eventually attributed to regioisomeric tetracyclic furoindolines $\mathbf{4 4}$ for the major compound and $\mathbf{4 5}$ for the minor isomer which were both obtained as single diastereoisomers. A trans-relationship between the two ring junctions was observed for 44, while a cis-relationship was noticed for 45. At first sight, we were puzzled by the mechanism of this reaction which involved the formation of 2 cycles, 3 bonds and 4 stereocenters. Then we realized that $\mathbf{4 4}$ and $\mathbf{4 5}$ were the product of a formal $(3+2)$ cycloaddition between N-Ac indole and dipole XVII. The latter would arise from an interrupted iso-Nazarov cyclization. ${ }^{29}$ According to our proposed mechanism, $\mathrm{FeCl}_{3}$ plays a double role in this reaction: activation of the $\mathrm{N}-\mathrm{Ac}$ indole and of the dienal. For instance, in 2014 Mischne showed the ability of $\mathrm{FeCl}_{3}$ to promote interrupted vinylogous iso-Nazarov reactions. ${ }^{30}$ The complexation by the carbonyl group of the dienal would induce 
the formation of a cyclic oxyallyl cation XVI via a stereospecific conrotatory $4 \pi$ electrocyclization of XV. Instead of the elimination of a proton to yield cyclopentadienol XVIII and then cyclopentenone 46, oxyallyl cation XVII reacts with the activated $\mathrm{N}$-Ac indole dipolarophile Ia. As the major pathway the now C2nucleophilic position of the indole adds to the carbocation of XVII and the resulting electrophilic C3-position of the indole is trapped by the oxygen atom of the dipole. Furthermore, minor cycloadduct $\mathbf{4 5}$ was produced from the classical reactivity of indoles in cycloadditions. We have therefore performed a domino interrupted iso-Nazarov/dearomative $(3+2)$-cycloaddition of electrophilic indoles promoted by $\mathrm{FeCl}_{3}$ (Scheme 15). Good yields and regioselectivities were obtained with substituents such as halogens $(\mathrm{F}, \mathrm{Cl}, \mathrm{Br})$ or electron-donating groups on the benzene part of the indole. Then, we have shown that the nature of the substituent borne by the $\gamma$ position of the 2,4-dienal $\mathbf{4 2}$ is important for this transformation. The best yields were obtained with a phenyl group at this position. Replacement of the latter with by a methyl led to a decrease of the yield, while a hydrogen led to no cycloaddition. Indeed, stabilization of carbocation intermediates XVI and XVII is increased with a phenyl group over a methyl group or a hydrogen. It should be noted that our consortium has also discovered that alkenes substituted by an electron-withdrawing groups could react in a [4+2] cycloaddition with cyclopentadienol XVIII (not shown). ${ }^{31}$

\section{Radical-Mediated Dearomatization of Indoles for the Synthesis of Spirocyclic Indolines}

After demonstrating that the dearomatization of indoles could be effected via the generation of electrophilic indole intermediates, we turned our attention to study a radical-mediated approach. Two types of radical were chosen, perfluorinated-carbon and phosphonyl radicals, in order to introduce functional groups, which present unique biological properties.

Modified Minisci-type reactions constituted a strategy of interest for the functionalization of heteroarenes and indoles. ${ }^{32}$ Generation of a free-radical intermediate in oxidative conditions is followed by its addition at the C2-position of indoles with the formation of a new bond (Scheme 16). Further oxidation of the radical XIX formed at C3 lead to carbocation $\mathbf{X X}$. Indeed, fast aromatization generally yields functionalized indole 48 . In our interrupted Minisci-type strategy, we desired to intercept carbocation $\mathbf{X X}$ with a nucleophile before the elimination of the proton from the C2-position which would give us access to indoline 47. It was in fact inspired by our work on the synthesis of benzofuro[3,2- $b]$ indolines via the addition of a phenoxyl radical to $\mathrm{N}$-Ac indoles in presence of $\mathrm{FeCl}_{3}$ (cf Scheme 10). ${ }^{20}$ Therefore, our first thought was to take advantage of the unique reactivity of $\mathrm{FeCl}_{3}$-activated $\mathrm{N}$-Ac indoles intermediates Ia to add a diverse array of radicals at the C2-position of indoles. It turned out that $\mathrm{FeCl}_{3}$ was not needed. As a precedent, Shi demonstrated that it was possible to add azide radicals into indoles 49 with a nucleophilic entity on the C3-position which can trap the carbocation at C3 leading to 2-azido-3,3-spirocyclic indolines $\mathbf{5 0 . 3 3}$

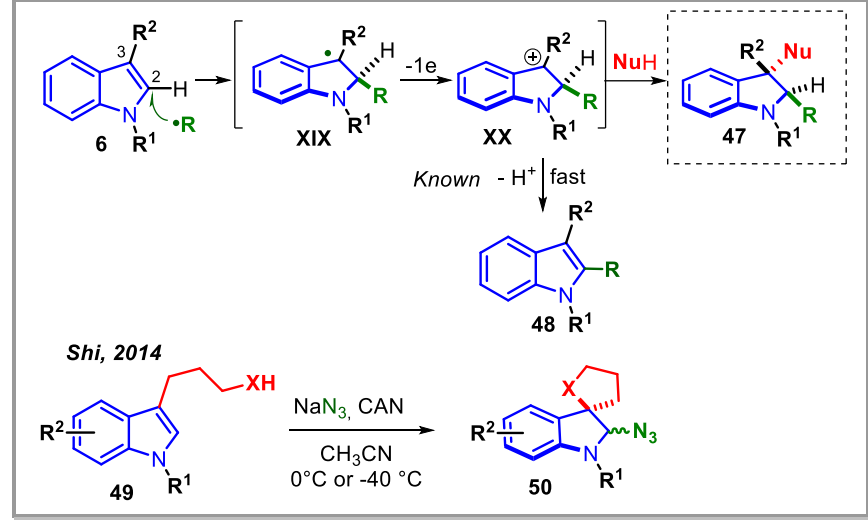

Scheme 16 Radical-mediated functionalization versus dearomatization of indoles.

Following this concept, a diastereoselective dearomative 3,3spirocyclization of indoles was reported by deploying the addition of trifluoromethyl radical XXI at the C2 position of indoles 49. ${ }^{34}$ This radical was generated from the oxidation of sodium trifluoromethylsulfinate $\mathbf{5 1}$, also known as the Langlois' reagent, ${ }^{35}$ with ceric ammonium nitrate (Scheme 17). The sodium 1,1-difluorethylsulfinate could also be used to introduce a 1,1difluoroethyl group. The spirocyclization proceeds with primary and tertiary alcohols, carboxylic acids and sulfonamide as internal nucleophiles with a complete trans diastereoselctivity between the trifluoromethyl group and the nucleophilic entity of 2-trifluoromethyl-3,3-spiroindolines 52. Different functional groups on the benzene ring and electron withdrawing groups on the nitrogen of the indole nucleus were well tolerated. We have thus merge a spirocyclic indoline with a fluorinated functionality which are both biologically relevant entities. Yu and Lan reported a concomitant and related transformation with the Togni's reagent $\mathbf{5 4}$ instead of the Langlois'reagent from gramines $\mathbf{5 3}$ and $\mathrm{CO}_{2}$ to obtain spirocyclic carbamates $\mathbf{5 5} .^{36}$

In an analog manner, we have recently published the synthesis of 2-phosphono-3,3-spirondolines $\mathbf{5 7}$ by using phosphites $\mathbf{5 6}$ as source of phosphonyl radicals XXII in presence of manganese triacetate as oxidant. ${ }^{37}$ This method allows to embedded into a spirocyclic indoline framework, $\alpha$-aminophosphonates which are important biological compounds. This transformation with a broad array of phosphonyl radicals works with an excellent trans diaseteroselectivity with moderate yields (22-60\%) and permits only alcohols as nucleophile (Scheme 17). It should be noted that these 2-phosphonoindolines $\mathbf{5 7}$ are quite sensitive to acid or basic conditions and tends to aromatize via elimination of the acidic hydrogen at the $\mathrm{C} 2$ position.

Worthy of note, Wang and collaborators described the synthesis of related 3,3-spirocyclic indolines via the intramolecular addition of radicals, generated by photoredox catalysis, to the C3-position of the indole, followed by the trapping of a C2carbocation by a nucleophile. ${ }^{38}$ 


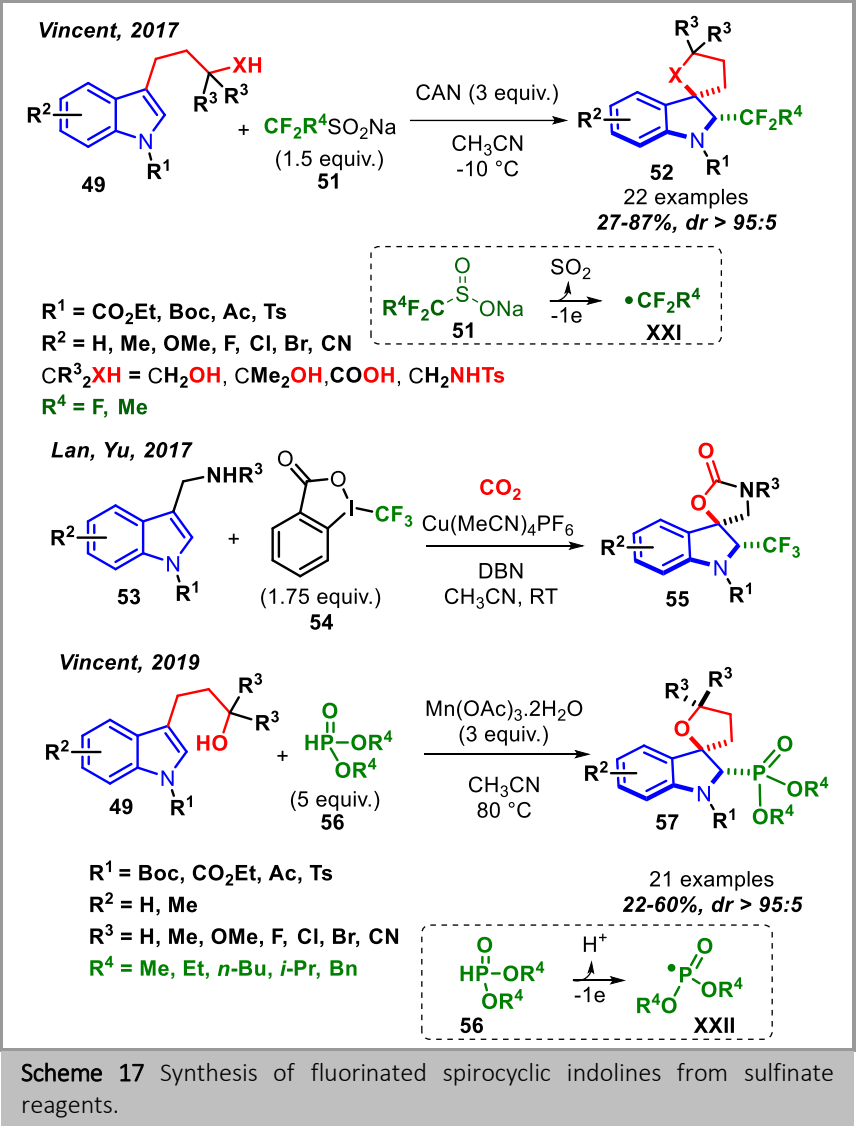

\section{Electrochemical Dearomatization of Indoles}

\subsection{Direct electrochemical oxidation of indoles}

While these radical mediated dearomatization of indoles were efficient methods to access three-dimensional indoline frameworks, they suffer from the use of excess amounts of oxidative reagents. Indeed, in the last decade, photoredox catalysis has emerged as an efficient method to generate radical intermediates in more sustainable conditions and is employed in indole dearomatization. ${ }^{38,39}$ On the other hand, electrochemistry also became over the last few years, a powerful synthetic tool in organic chemistry to avoid the use of stoichiometric amounts of oxidants or reductants. ${ }^{40}$ The selective difunctionalization of alkenes is an important application of electrochemistry, ${ }^{41}$ yet he related electrochemical dearomatization has been less studied. ${ }^{42}$

As mentioned above, in 2017 Lei and co-workers deployed electrochemistry to improve our oxidative coupling between $\mathrm{N}$ Ac indoles and phenols (Scheme 11). ${ }^{21}$ In this transformation, the $\mathrm{N}$-Ac indole is considered to be oxidized at the anode into a radical cation. Therefore, due to our expertise in indole dearomatization, we were interested to also enter the field of electrochemically-induced dearomative process. Since we had no experience of electrochemistry, our endeavor was facilitated by the recent commercially arability of ElectraSyn 2.0, an easy-to handle apparatus for electrosynthesis. We decided to trap indolyl radical cations generated at the anode by different nucleophiles in order to obtain difunctionalized indolines (Scheme 18). Apart from the work of Lei, few precedents for the interceptions of such radical cations were known. In 2004, Royer reported the dimethoxylation of one tetrahydro- $\beta$-carboline $\mathbf{5 8}$ and in 2010,43 Fuchigami described the difluorination of indoles. ${ }^{44}$

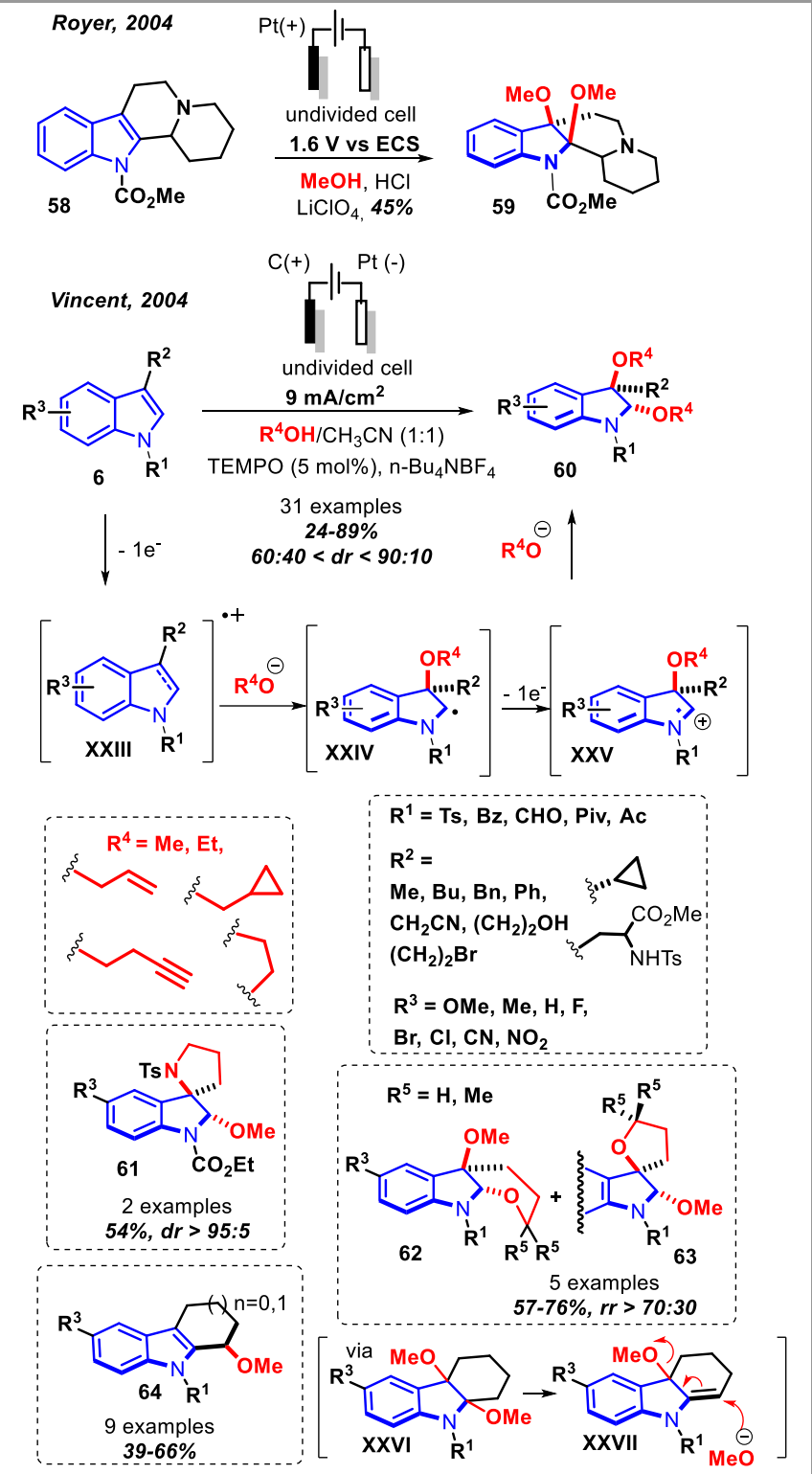

Scheme 18 Electrochemical dearomative difunctionalization of indoles with alcohols.

This approach allowed us to develop an efficient and general electrochemical 2,3-difunctionalizations of indoles (Scheme 18). ${ }^{45}$ Building from the work of Royer, the formation of two C-O bonds was first studied by using methanol as co-solvent with acetonitrile in an undivided cell with a constant current between a graphite anode and a platinum-plated cathode. Based on different control experiments, the mechanism proposed for this electrochemical 2,3-dialkoxylation involves an anodic oxidation of the N-substituted indole $\mathbf{6}$ into radical cation intermediate XXIII which can be intercepted by a alkoxide anion, produced by a cathodic reduction. Subsequent single electron-transfer of XXIV led to iminium ion $\mathbf{X X V}$ and then to the 2,3-dialkoxyindolines 60. ${ }^{46}$ Good yields of dimethoxyindolines $\mathbf{6 0}$ were obtained in favor of the trans diasteroisomer. The electrolysis can also be performed with different alcohols like ethanol, allyl alcohol, cyclopropyl methanol, homopropargyl alcohol and ethylene glycol (Scheme 18). Various electron-withdrawing groups on indole nitrogen are tolerated in this transformation.

Concerning the electronic effects on the benzene part of the indole, both electron donating and electron-withdrawing groups 
afforded the expected dialkoxylated indolines $\mathbf{6 0}$. This reaction proceeds well with alkyl groups or phenyl substituents at the C3 position and it can preserve different functional groups on the C3-side chain. Interestingly, no intramolecular trapping was observed from tryptophol and tryptophan derivatives (two carbons on the C3-side chain). In contrast, we have observed that starting from homotryptophol or homotryptamine derivatives (three carbons on the C3-side chain) led to intramolecular trapping by the appended nucleophile. Methoxytetrahydropyranoindoline $\mathbf{6 2}$ as the major product ${ }^{47}$ with some 3,3-spirocyclic-2-methoxy indoline $\mathbf{6 3}$ were obtained the case of an alcohol as the intramolecular nucleophile. An inversion of the regioselectivity was observed with a sulfonamide as internal nucleophile since trans-3,3-spirocyclic-2-methoxy-indolines $\mathbf{6 1}$ were selectively obtained. ${ }^{48}$

On an other side, when we applied the same electrochemical conditions to tetrahydrocarbazoles, $\alpha$-monomethoxylated indoles 64 were isolated instead of the 2,3-dimethoxylation products. It seems obvious that after the dearomatvive 2,3dimethoxylation, elimination of one methoxy lead to enamide XXVII on which allylic nucleophilic substitution by methanol occurs.

In order to improve the diversity of this process, the formation of two $\mathrm{C}-\mathrm{N}$ bonds was then achieved by using trimethylsilyl azide as nucleophile (Scheme 19).

Undivided cell

This electrochemical diazidation reaction gave selectively trans2,3-diazide indolines 65 with good yields from 3-substituted indoles. ${ }^{45,49}$ In the case of $\mathrm{N}$-Ts tetrahydrocarbazoles or cyclopentaindole, the dearomatized cis-products 66 were isolated. As synthetic applications, we have shown that this diazide compounds can be reduced to amines or engaged in a double click reaction to obtain bistriazoles (not shown). It should be mentioned than Lin reported in 2017, a general electrochemical diazidation of alkenes, from which one example of dearomatization of N-Ts indole was reported via the metalcatalyzed addition of an azide radical to the double bond. ${ }^{50,51}$ Other research groups have also further performed dearomative difunctionalization of $\mathrm{N}$-acyl indoles via electrochemicallygenerated radical cation intermediates. ${ }^{52}$

\subsection{Indirect electrochemical oxidation of indoles}

Alternatively to this direct anodic oxidation approach, we were also looking to perform an indirect electrochemical dearomatization of the indole nucleus.

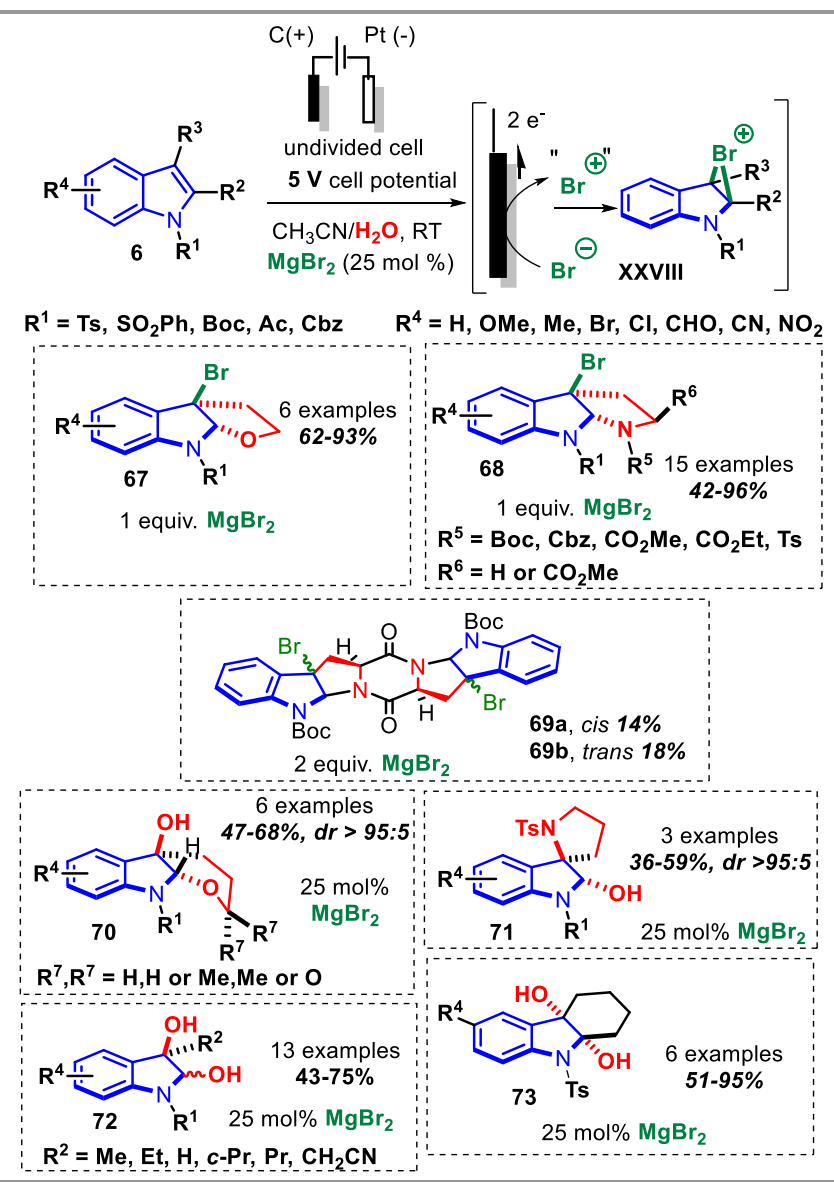

Scheme $20 \mathrm{MgBr}_{2}$-mediated electrochemical dearomative bromocyclization, hydroxycyclization and dihydroxylation of indoles.

It is known that 3-unsubsituted indoles could be halogenated into 3-haloindoles by electrolysis in presence of halides. ${ }^{53}$ It inspired us to generate in-situ an electrophilic bromine reagent via the anodic oxidation of a bromide salt which could react with the indole nucleus to form bromonium ion XXVIII and could be intercepted with an internal or external nucleophile. We identify that such a process could be achieved with $\mathrm{MgBr}_{2}$ in an undivided cell with a graphite anode and a platinum-plated cathode with a constant cell potential of $5 \mathrm{~V}$ in a mixture of acetonitrile and water at room temperature without the need of an additional electrolyte (Scheme 20). Therefore, we achieved the conversion of tryptophol, tryptamine and tryptophan derivatives into bromofuranoindolines 67 and bromopyrroloindolines $\mathbf{6 8 . 5 4 , 5 5}$ Various electron-withdrawing groups on the indole nitrogen as well as halogens or donating groups on the benzene part of the indole permit the successful formation of the bromocyclized products. From tryptamines and tryprtophans, different associations of orthogonal protecting groups of the indole and amine nitrogens were tolerated. Cyclization of tryptophan derivatives proceeds with an exo-selectivity. The bromopyrroloindolines $\mathbf{6 8}$ obtained are important intermediates for the total synthesis of natural products of peptidic origin via stereospecific substitution reactions of the carbon-bromide 
bond. For instance, we achieved the electrochemical doublebromocyclization of a diketopiperazine from two tryptophan units. We obtained a separable mixture of the cis and trans double-cyclized products 69a and 69b which are respectively intermediates for the synthesis of (-)-epi-amauromine and (+)novoamauromine as described by Tokuyama. 56

Shortly after our report, the group of Lei reported a related electrochemical halocyclization of tryptophol and tryptamine derivatives with lithium halides and $\mathrm{Mn}(\mathrm{OAc})_{2}$ as catalyst. ${ }^{57}$

In an extension of this work, ${ }^{58}$ we showed that adding one carbon to the side chain at the C3-position, did not lead to the corresponding brominated-cyclized product. In an analogous manner with the direct oxidation approach (cf Scheme 18), 3hydroxy-tetrahydropyranoindolines $\mathbf{7 0}$ were formed from alcohols and carboxylic acids, probably via a SN1 process from the corresponding 3-bromo-tetrahydropyranoindolines (Scheme 20). Inversion of regioselectivity was noticed from a pendant sulfonamide nucleophile with the synthesis of 2-hydroxy-3,3spiroindolines $\mathbf{7 1}$. In these cases, only a substoichiometric amount of $\mathrm{MgBr}_{2}$, as a redox mediator, is necessary.

Starting from substrates without an internal nucleophilic entity, a dearomative dihydroxylation is observed in these electrochemical conditions, most likely involving the double addition of water to bromonium bridge XXVIII (Scheme 20). The diastereoselctivity of formation of 2,3-dihydroxyindolines $\mathbf{7 2}$ from 3-substituted indoles depends on the substituent of the indole nitrogen: a tosyl group lead mainly to a cisdiastereoselectivity while an acetyl delivers the trans isomer as the major compound. Both electron-donating groups, halogens and electron-withdrawing groups on the benzene part of indole allowed the formation of dihydroxyindolines. Various substituents at the C3-position such as alkyl groups or the presence of a nitrile on the C3-alkyl side chain are tolerated by this transformation. Interestingly, these mild conditions can be applied to tetrahydrocarbazoles to lead to cis-2,3dihydroxyindolines $\mathbf{7 3}$ without the formation of $\alpha$ hydroxyindoles as in it is the case for the direct anodic oxidation in methanol (cf Scheme 18).

\section{Conclusion}

The structural complexity as well as the biological importance of three-dimensional indoline derivatives have prompted chemists including our lab, to develop numerous elegant methods for their preparation. In this account, we wished to summarize our recent works related to dearomatization reactions of indole.

Our interest in this domain brought us to elaborate an original strategy based on the reversion of polarity of the indole nucleus or in other words: an "umpolung of indole". We have shown that the $\mathrm{C} 3$ position of $\mathrm{N}-\mathrm{Ac}$ indoles, in the presence of $\mathrm{FeCl}_{3}$ or $\mathrm{TfOH}$, can be trapped by various $\pi$-nucleophiles, mainly electron-rich arenes but also allylsilanes. The ability of this mode of activation to be combined with other reactions was shown by developing a domino interrupted iso-nazarov/dearomative $(3+2)$ cycloaddition of electrophilic indoles leading to complex polyheterocyclic structures in a collaborative work. We are thankful to serendipity for the discovery of unexpected reactivities.
On the other hand, the generation of trifluoromethyl or phosphonyl radicals and their addition to indoles containing a pendant nucleophile led to the development of a diastereoselective dearomative 3,3-spirocyclization of indoles. This strategy should be amenable to various other radical sources and thus lead to the generation of scaffolds of potential interest for drug discovery.

Finally, in order to perform dearomatization reactions without the need to use an excess of oxidative reagents, we turned our attention towards electrochemistry. A first approach proceeds via direct anodic oxidation of the $\mathrm{N}$-substituted indole into a radical cation and its reaction with alcohols or azides yielding three-dimensional indolines. In contrast, a second approach involves an indirect electrochemical oxidation of the indole nucleus mediated by the oxidation of $\mathrm{MgBr}_{2}$ into a bromonium ion which is involved in the dihydroxylation, hydroxycyclization or bromocyclization of indole derivatives. For instance, we were able to convert tryptophol, tryptamine and tryptophan derivatives into 3a-bromofuranoindolines and 3abromopyrroloindolines which are versatile building blocks.

In parallel to the work presented in this account, we also study oxidative couplings of indoles in the context of the total synthesis of natural products. 59

We hope that this summary will provide a useful perspective of our approach in the field of indole dearomatization towards the synthesis of complex molecules with potential biological interest.

\section{Funding Information}

The research leading to the results summarized in this account has received funding from the ANR (ANR-17-CE07-0050 "ArDCo" and ANR12-JS07-0002 "CouPhIn), the European Union's Seventh Framework Programme FP7/2007-2013/ under REA grant agreement $n^{\circ} 623422$ ("ElectrIndole"), Labex CHARMMMAT (ANR-11-LABX-0039), the China Scholarship Council, the "Ministère de l'Enseignement Supérieur, de la Recherche et de l'Innovation, the Université Paris-Sud and the CNRS.

\section{Acknowledgment}

We gratefully thank all the talented and dedicated $\mathrm{PhD}$ students and postdoctoral researchers that contributed to this work since 2011 as well as the very fruitful collaborations.

\section{References}

(1) Lovering, F.; Bikker, J.; Humblet, C. J. Med. Chem. 2009, 52, 67526756.

(2) (a) Roche, S. P.; Youte Tendoung, J.-J.; Tréguier, B. Tetrahedron 2015, 71, 3549-3591; (b) Denizot, N.; Tomakinian, T.; Beaud, R.; Kouklovsky, C.; Vincent, G. Tetrahedron Lett. 2015, 56, 4413-4429.

(3) (a) Asymmetric Dearomatization Reactions; You, S.-L., Ed.; WileyVCH Verlag GmbH \& Co. KGaA, 2016; (b) Zheng, C.; You, S.-L. Chem 2016, 1, 830-857; (c) Zhuo, C.-X.; Zhang, W.; You, S.-L. Angew. Chem. Int. Ed. 2012, 51, 12662-12686; (d) Roche, S. P.; Porco Jr., J. A. Angew. Chem. Int. Ed. 2011, 50, 4068-4093.

(4) Wu, Q.-X.; Crews, M. S.; Draskovic, M.; Sohn, J.; Johnson, T. A.; Tenney, K.; Valeriote, F. A.; Yao, X.-J.; Bjeldanes, L. F.; Crews, P. Org. Lett. 2010, 12, 4458-4461

(5) (a) Beaud, R.; Tomakinian, T.; Denizot, N.; Pouilhès, A.; Kouklovsky, C.; Vincent, G. Synlett, 2015, 26, 432-440; (b) Ito, Y.; Ueda, M.; Miyata, O. Heterocycles, 2014, 89, 2029-2052; (c) Lachia, M.; Moody, C. J. Nat. Prod. Rep. 2008, 25, 227-253.

(6) (a) Burgett, A. W. G.; Li, Q.; Wei, Q.; Harran, P. G.; Angew. Chem. Int. Ed. 2003, 42, 4961-4966; for an electrochemical version: (b) Ding, H.; DeRoy, P. L.; Perreault, C.; Larivée, A.; Siddiqui, A.; Caldwell, C. 
G.; Harran, S.; Harran, P. G. Angew. Chem. Int. Ed. 2015, 54, 48184822.

(7) (a) Chan, C.; Li, C.; Zhang, F.; Danishefsky, S. J. Tetrahedron Lett. 2006, 47, 4839-4841; (b) Nicolaou, K. C.; Majumder, U.; Roche, S. P.; Chen, D. Y.-K.. Angew. Chem. Int. Ed. 2007, 46, 4715-4718.

(8) (a) Zhao, J.-C.; Yu, S.-M.; Liu, Y.; Yao, Z.-J. Org. Lett. 2013, 15, 4300 4303; (b) Zhao, J.-C.; Yu, S.-M.; Qui, H.-B.;Yao, Z.-J. Tetrahedron 2014, 70, 3197-3210.

(9) (a) Cerveri, A.; Bandini, M. Chin. J. Chem. 2020, 38, 287-294; (b) Bandini, M. Org. Biomol. Chem. 2013, 11, 5206-5212; (c) Kishbaugh, T. L. S. Heterocyclic Scaffolds II; Gribble, G. W., Ed.; In Topics in Heterocyclic Chemistry; Springer: Berlin Heidelberg, 2010, 117-140.

(10) (a) Nishida, K.; Yanase, E.; Nakatsuka, S.-i. ITE, Lett. Batterie, New Technol. Med. 2006, 7, 59-62; (b) Tajima, N.; Hayashi, T.; Nakatsuka, S.-N. Tetrahedron Lett. 2000, 41, 1059-1062;

(11) Beaud, R.; Guillot, R.; Kouklovsky, C.; Vincent, G. Angew. Chem. Int. Ed. 2012, 51, 12546-12550.

(12) Beaud, R.; Guillot, R.; Kouklovsky, C.; Vincent, G. Chem. - Eur. J. 2014, 20, 7492-7500.

(13) For a review: James, M. J.; O’Brien, P.; Taylor, R. J. K.; Unsworth, W. P. Chem. - Eur. J. 2016, 22, 2856-2881.

(14) Nandi, R. K.; Guillot, R.; Kouklovsky, C.; Vincent, G. Org. Lett. 2016, 18, 1716-1719.

(15) Nandi, R. K.; Ratsch, F.; Beaud, R.; Guillot, R.; Kouklovsky, C.; Vincent, G. Chem. Commun. 2016, 52, 5328-5331.

(16) Morimoto, N.; Morioku, K.; Suzuki, H.; Takeuchi, Y.; Nishina, Y. Org. Lett. 2016, 18, 2020-2023.

(17) Beaud, R.; Nandi, R. K.; Perez-Luna, A.; Guillot, R.; Gori, D.; Kouklovsky, C.; Ghermani, N.-E.; Gandon, V.; Vincent, G. Chem. Commun. 2017, 53, 5834-5837.

(18) Nandi, R. K.; Perez-Luna, A.; Gori, D.; Beaud, R.; Guillot, R.; Kouklovsky, C.; Gandon, V.; Vincent, G. Adv. Synth. Catal. 2018, 360, 161-172.

(19) Huang, Z.; Jin, L.; Feng, Y.; Peng, P.; Yi, H.; Lei, A. Angew. Chem. Int. Ed. 2013, 52, 7151-7155.

(20) Tomakinian, T.; Guillot, R.; Kouklovsky, C.; Vincent, G. Angew. Chem. Int. Ed. 2014, 53, 11881-11885.

(21) Liu, K.; Tang, S.; Huang, P.; Lei, A. Nat. Commun. 2017, 8, 775.

(22) Li, L.; Yuan, K.; Jia, Q.; Jia, Y. Angew. Chem. Int. Ed. 2019, 58, $6074-$ 6078.

(23) Wu, J.; Nandi, R. K.; Guillot, R.; Kouklovsky, C.; Vincent, G. Org. Lett 2018, 20, 1845-1848.

(24) (a) Bubnov, Y. N.; Zhun', I. V.; Klimkina, E. V.; Ignatenko, A. V.; Starikova, Z. A. Eur. J. Org. Chem. 2000, 3323-3327; (b) Nowrouzi, F.; Batey, R. A. Angew. Chem. Int. Ed. 2013, 52, 892-895; (c) Alam, R.; Diner, C.; Jonker, S.; Eriksson, L.; Szabó, K. J. Angew. Chem. Int. Ed. 2016, 55, 14417-14421.

(25) Zhu, M.; Zheng, C.; Zhang, X.; You, S.-L. J. Am. Chem. Soc. 2019, 141, 2636-2644.

(26) Firooznia, F.; Kester, R. F.; Berthel, S. J. Heterocyclic Scaffolds II; Gribble, G. W., Ed.; In Topics in Heterocyclic Chemistry; Springer: Berlin Heidelberg, 2010, 283-326.

(27) (a) Portalier, F.; Bourdreux, F.; Marrot, J.; Moreau, X.; Coeffard, V.; Greck, C. Org. Lett. 2013, 15, 5642-5645; (b) Pantaine, L.; Coeffard, V.; Moreau, X.; Greck, C. Eur. J. Org. Chem. 2015, 2005-2011.

(28) Marques, A.-S.; Coeffard, V.; Chataigner, I.; Vincent, G.; Moreau, X. Org. Lett. 2016, 18, 5296-5299.

(29) For a review on the iso-Nazarov reaction: (a) Riveira, M. J. ; Marsili, L. A. ; Mischne, M. Org. Biomol. Chem. 2017, 15, 9255-9274; for a review on interrupted Nazarov processes: (b) A. V. Yadykov, V. Z. Shirinian, Adv. Synth. Catal. 2020, 362, 702-703.

(30) Riveira, M. J.; Mischne, M. P. J. Org. Chem. 2014, 79, 8244-8255.

(31) (a) Marques, A.-S.; Duhail, T.; Marrot, J.; Chataigner, I.; Coeffard, V.; Vincent, G.; Moreau, X. Angew. Chem. Int. Ed. 2019, 58, 9969-9973; (b) Marques, A.-S.; Marrot, J.; Chataigner, I.; Coeffard, V.; Vincent, G.; Moreau, X. Org. Lett. 2018, 20, 792-795.

(32) Seminal contribution: (a) Minisci, F.; Bernardi, R.; Bertini, F.; Galli, R.; Perchinummo, M. Tetrahedron 1971, 27, 3575-3579; for review: (b) Duncton, M. A. J. MedChemComm 2011, 2, 1135-1161; for the synthesis of 2-trifluoromethylindoles: (c) Ding, B.; Weng, Y.; Liu, Y.; Song, C.; Yin, L.; Yuan, J.; Ren, Y.; Lei, A.; Chiang, C.-W. Eur. J. Org. Chem. 2019, 7596-7605; for the synthesis of 2phosphonoindoles: (d) Chen, L.; Zou, Y.-X. Org. Biomol. Chem. 2018, $16,7544-7556$

(33) Li, J.; Liu, M.; Li, Q.; Tian, H.; Shi, Y. Org. Biomol. Chem. 2014, 12 9769-9772.

(34) Ryzhakov, D.; Jarret, M.; Guillot, R.; Kouklovsky, C.; Vincent, G. Org Lett. 2017, 19, 6336-6339.

(35) (a) Langlois, B. R.; Laurent, E.; Roidot, N. Tetrahedron Lett. 1991 32, 7525-7528; (b) Fujiwara, Y.; Dixon, J. A.; O’Hara, F.; Funder, E. D.; Dixon, D. D.; Rodriguez, R. A.; Baxter, R. D.; Herlé, B.; Sach, N.; Collins, M. R.; Ishihara, Y.; Baran, P. S. Nature 2012, 492, 95-99; (c) Lefebvre, Q.; Synlett, 2017, 28, 19-23.

(36) Ye, J.-H.; Zhu, L.; Yan, S.-S.; Miao, M.; Zhang, X.-C.; Zhou, W.-J.; Li, J.; Lan, Y.; Yu, D.-G. ACS Catal. 2017, 7, 8324-8330.

(37) Ryzhakov, D.; Jarret, M.; Baltaze, J.-P.; Guillot, R.; Kouklovsky, C.; Vincent, G. Org. Lett. 2019, 21, 4986-4990.

(38) (a) Wang, Q.; Qu, Y.; Xia, Q.; Song, H.; Song, H.; Liu, Y.; Wang, Q. Adv. Synth. Catal. 2018, 360, 2879-2884; (b) Wang, Q.; Qu, Y.; Xia, Q.; Song, H.; Song, H.; Liu, Y.; Wang, Q. Chem. - Eur. J. 2018, 24, 1128311287.

(39) Selected examples: (a) Zhang, C.; Li, S.; Bureš, F.; Lee, R.; Ye, X.; Jiang, Z. ACS Catal. 2016, 6, 6853-6860; (b) Schilling, W.; Zhang, Y.; Riemer, D.; Das, S. Chem. - Eur. J. 2020, 26, 390-395.

(40) (a) Francke, R.; Little, R. D. Chem. Soc. Rev. 2014, 43, 2492-2521; (b) Horn, E. J.; Rosen, B. R.; Baran, P. S. ACS Cent. Sci. 2016, 2, 302308; (c) Yan, M.; Kawamata, Y.; Baran, P. S. Chem. Rev. 2017, 117, 13230-13319; (d) Wiebe, A.; Gieshoff, T.; Möhle, S.; Rodrigo, E.; Zirbes, M.; Waldvogel, S. R. Angew. Chem. Int. Ed. 2018, 57, 55945619; (e) Möhle, S.; Zirbes, M.; Rodrigo, E.; Gieshoff, T.; Wiebe, A.; Waldvogel, S. R. Angew. Chem. Int. Ed. 2018, 57, 6018-6041; (f) Tang, S.; Liu, Y.; Lei, A. Chem 2018, 4, 27-45.

(41) (a) Martins, G. M.; Shirinfar, B.; Hardwick, T.; Ahmed, N. ChemElectroChem 2019, 6, 1254-1254; (b) Sauer, G. S.; Lin, S. ACS Catal. 2018, 8, 5175-5187; (c) Feng, R.; Smith, J. A.; Moeller, K. D. Acc. Chem. Res. 2017, 50, 2346-2352.

(42) Lv, S.; Zhang, G.; Chen, J.; Gao, W. Adv. Synth. Catal. 2020, 362, 462477.

(43) Royer, J.; Planas, L.; Martens, T.; Billon-Souquet, F. Heterocycles 2004, 63, 765-771.

(44) Yin, B.; Wang, L.; Inagi, S.; Fuchigami, T. Tetrahedron 2010, 66, 6820-6825.

(45) Wu, J.; Dou Y.; Guillot, R.; Kouklovsky, C.; Vincent, G. J. Am. Chem. Soc. 2019, 141, 2832-2837.

(46) For selected non-electrochemical dearomative dialkoxylation or dihydroxylation of indoles: (a) Kwon, S.; Kuroki, N. Chem. Lett. 1980, 9, 237-238; (b) Vice, S. F.; Dmitrienko, G. I. Can. J. Chem. 1982, 60, 1233-1237; (c) Kawasaki, T.; Chien, C.-S.; Sakamoto, M. Chem. Lett. 1983, 12, 855-858; (d) Takayama, H.; Misawa, K.; Okada, N.; Ishikawa, H.; Kitajima, M.; Hatori, Y.; Murayama, T.; Wongseripipatana, S.; Tashima, K.; Matsumoto, K.; et al.. Org. Lett. 2006, 8, 5705-5708; (e) Silva Jr, L. F.; Craveiro, M. V.; Gambardella, M. T. P. Synthesis 2007, 3851-3857; (f) Liu, Q.; Zhao, Q. Y.; Liu, J.; Wu, P.; Yi, H.; Lei, A. Chem. Commun. 2012, 48, 3239-3241.

(47) For the synthesis of related hydroxypyranoindoline derivatives via dearomatization: (a) Hino, T.; Miura, H.; Murata, R.; Nakagawa, M. Chem. Pharm. Bull. 1978, 26, 3695-3703; (b) Pathak, T. P.; Gligorich, K. M.; Welm, B. E.; Sigman, M. S. J. Am. Chem. Soc. 2010 132, 7870-7871; (c) Han, L.; Zhang, W.; Shi, X.-X.; You, S.-L. Adv. Synth. Catal. 2015, 357, 3064-3068.

(48) For the synthesis of related 3,3-spiro-3-amino-2-hydroxyindoline derivatives via dearomatization: (a) Braun, N. A.; Bray, J. D.; Ciufolini, M. A. Tetrahedron Lett. 1999, 40, 4985-4988; (b) Zhang, Y.-Q. ; Yuan, Y.-A.; Liu, G.-S.; Xu, H. Org. Lett. 2013, 15, 3910-3913; (c) Zhang, Z.; Li, X.; Song, M.; Wan, Y.; Zheng, D.; Zhang, G.; Chen, G. J. Org. Chem. 2019, 84, 12792-12799. 
(49) For selective non-electrochemical dearomative diazidations of indoles: (a) Tamura, Y.; Kwon, S.; Tabusa, F.; Ikeda, M. Tetrahedron Lett. 1975, 16, 3291-3294; (b) Tamura, Y.; Chun, M. W.; Kwon, S.; Said, M. B.; Okada, T.; Ikeda, M. Chem. Pharm. Bull. 1978, 26, 35153520; (c) Moriarty, R. M.; Khosrowshahi, J. S. A. Tetrahedron Lett. 1986, 27, 2809-2812; (d) Nocquet-Thibault, S.; Rayar, A.; Retailleau, P.; Cariou, K.; Dodd, R. H. Chem. - Eur. J. 2015, 21, 14205-14210; (e) Yuan, Y.-A.; Lu, D.-F.; Chen, Y.-R.; Xu, H. Angew. Chem. Int. Ed. 2016, 55, 534-538; (f) Shen, S.-J.; Zhu, C.-L.; Lu, D.-F.; $\mathrm{Xu}, \mathrm{H}$. ACS Catal. 2018, 8, 4473-4482.

(50) Fu, N.; Sauer, G. S.; Saha, A.; Loo, A.; Lin, S. Science 2017, 357, 575579.

(51) For an electrochemical diamination of indoles via a different pathway: Li, L.; Luo, S. Org. Lett. 2018, 20, 1324-1327.

(52) (a) Zhang, S.; Li, L.; Wu, P.; Gong, P.; Liu, R.; Xu, K. Adv. Synth. Catal. 2019, 361, 485-489; (b) Liu, K.; Song, W.; Deng, Y.; Yang, H.; Song, C.; Abdelilah, T.; Wang, S.; Cong, H.; Tang, S.; Lei, A. Nat. Commun. 2020, 11, 3; (c) Song, C. ; Liu, K. ; Jiang, X.; Dong, X.; Weng, Y.; Chiang, C.-W.; Lei, A. Angew. Chem Int. Ed. 2020, 59, 7193-7197.

(53) Sun, L.; Zhang, X. ; Li, Z. ; Ma, J.; Zeng, Z. ; Jiang, H. Eur. J. Org. Chem. 2018, 2018, 4949-4952.

(54) Wu, J.; Abou-Hamdan, H.; Guillot, R.; Kouklovsky, C.; Vincent, G. Chem. Commun. 2020, 56, 1713-1716.

(55) For the related synthesis of bromopyrroloindolines by in-situ oxidation of bromide salts with oxone: Xu J.; Tong, R. Green Chem. 2017, 19, 2952-2956.

(56) Hakamata, H.; Sato, S.; Ueda H.; Tokuyama, H. Org. Lett., 2017, 19, 5308-5311.

(57) Liu, K.; Deng, Y.; Song, W.; Song, C.; Lei, A. Chin. J. Chem. doi:10.1002/cjoc.202000194.
(58) Wu, J.; Guillot, R.; Kouklovsky, C.; Vincent, G. Adv. Synth. Catal. 2020, 362, 1712-1719.

(59) (a) Dou, Y.; Kouklovsky, C.; Gandon, V.; Vincent, G. Angew. Chem. Int Ed. 2020, 59, 1527-1531; (b) Denizot, N.; Guillot, R.; Kouklovsky, C.; Vincent, G. Synthesis, 2018, 50, 4823-4828; (c) Lachkar, D.; Denizot, N.; Bernadat, G.; Ahamada, K.; Beniddir, M. A.; Dumontet, V.; Gallard, J.-F.; Guillot, R.; Leblanc, K.; N'nang, E. O.; Turpi, V.; Kouklovsky, C.; Poupon, E.; Evanno, L.; Vincent, G. Nat. Chem. 2017, 9, 793-798; (d) Tomakinian, T.; Abou-Hamdan, H.; Denizot, N. Guillot, R.; Baltaze, J.-P.; Kouklovsky, C.; Vincent, G. Eur. J. Org. Chem. 2017, 2757-2763; (e) Denizot, N.; Pouilhès, A.; Cucca, M.; Beaud, R.; Guillot, R.; Kouklovsky, C.; Vincent, G. Org. Lett. 2014, 16, 5752-5755.

\section{Biosketches}

\begin{tabular}{|c|c|}
\hline & $\begin{array}{l}\text { Hussein Abou-Hamdan received a B.S. degree in } 2013 \text { from the Lebanese University in Beirut } \\
\text { and a M.S. degree in } 2015 \text { from Université Paris-Scalay (formerly Université Paris-Sud). In 2018, } \\
\text { he obtained his Ph.D. degree in Medicinal Chemistry from Université de Strasbourg under the } \\
\text { guidance of Dr. Laurent Désaubry. He is currently a post-doctoral research fellow in Dr. } \\
\text { Guillaume Vincent's research group at the Institut de Chimie Moléculaire et des Matériaux } \\
\text { d'Orsay (ICMMO) of Université Paris-Saclay where his research interests currently include } \\
\text { finding new reactions of dearomatization of indole in the context of the total synthesis of natural } \\
\text { product. }\end{array}$ \\
\hline & $\begin{array}{l}\text { Cyrille Kouklovsky was born in Paris, France, and educated at Paris-Sud University, Orsay, } \\
\text { France. He defended his PhD in } 1989 \text { under the supervision of Prof. Y. Langlois (CNRS, Gif-Sur- } \\
\text { Yvette, France), working on the cationic asymmetric Diels-Alder reaction. Then he moved to a } \\
\text { postdoctoral position in Prof. Steven V. Ley's research group (University of Cambridge, UK), } \\
\text { working on the total synthesis of rapamycin. In 1995, he was appointed as a CNRS research } \\
\text { fellow at Paris-Sud University, France, working on asymmetric dipolar cycloaddition reactions } \\
\text { and their synthetic applications. He was promoted as Professor of Chemistry in 2003. He } \\
\text { currently the MSMT team leader. His research interests are in the field synthetic methodology, } \\
\text { asymmetric synthesis and peptide synthesis. He was president of the Organic Chemistry Division } \\
\text { of the French Chemical Society from } 2015 \text { to } 2019 \text {. }\end{array}$ \\
\hline & $\begin{array}{l}\text { Guillaume Vincent is currently Directeur de Recherche at the CNRS. His research group at the } \\
\text { Institut de Chimie Moléculaire et des Matériaux d'Orsay (ICMMO) of Université Paris-Saclay } \\
\text { (formerly Université Paris-Sud) is interested in the total synthesis of natural products and in } \\
\text { indole dearomatization processes. After a Diplôme d'Ingénieur (2002) from Ecole Supérieure de } \\
\text { Chimie, Physique, Electronique de Lyon (CPE Lyon) with a one-year internship at Dupont } \\
\text { Pharmaceuticals (2000-2001) with Dr. Patrick Y. S. Lam, he obtained a Master (2002) and a PhD } \\
\text { (2005) degrees from Université Lyon-1 under the direction of Prof. Marco A. Ciufolini. After two } \\
\text { postdoctoral experiences with Prof. Robert M. Williams at Colorado State University and with } \\
\text { Prof. Louis Fensterbank and Prof. Max Malacria at Université Pierre et Marie Curie Paris-6, he } \\
\text { was appointed in } 2007 \text { Chargé de Recherche by the CNRS at ICMMO in the team directed by Prof. } \\
\text { Cyrille Kouklovsky. He obtained in 2018, the Jean-Marie Lehn Prize (Advanced Researcher Prize) } \\
\text { from the Organic Chemistry Division of the French Chemical Society. }\end{array}$ \\
\hline
\end{tabular}


